\title{
INDEX TO VOLUME XXI, 1906.
}

Abductor paralysis, supplementary report on case of (G. L. Richards) . $\quad{ }_{569}^{\text {PAK }}$

Abercrombie (Peter H.), case of new growth (? sarcoma) in the region of the right tonsil and anterior faucial pillar in a man further notes on the case of a patient aged seventy-five with sarcoma of the frontal sinuses (shown twice previously)

Abscess (dissecting) in region of mastoid process, but not invading it, deep penetration into neck (E. Urbantschitsch) . double optic neuritis (J. S. Barr) (retropharyngeal) caused by middle-ear suppuration (E. M.

Holmes)

$$
\text { (subdural) with chronic mastoid disease (H. S. Walker) }
$$

suboccipital, intercommunicating, complicating double mastoiditis (H. B. Hitz)

(sub-periosteal) of forehead, with thrombo-phlebitis of superior longitudinal sinus (V. Delsaux)

Acetozone inhalant

Adeno-carcinoma invading posterior fossa (H. Neumann)
Adenoid vegetations, removal of, through nasal passages by a new method (O. T. Freer)

Adenoids, diminution of dyslalia by, shown in case of cleft palate (W. Stuart-Low)

Adrenalin inhalant

injection of, in sarcoma of larynx (j. E. Rhodes)

Air-passages (upper), leukæmic changes in mucous membrane of (K. M. Menzel)

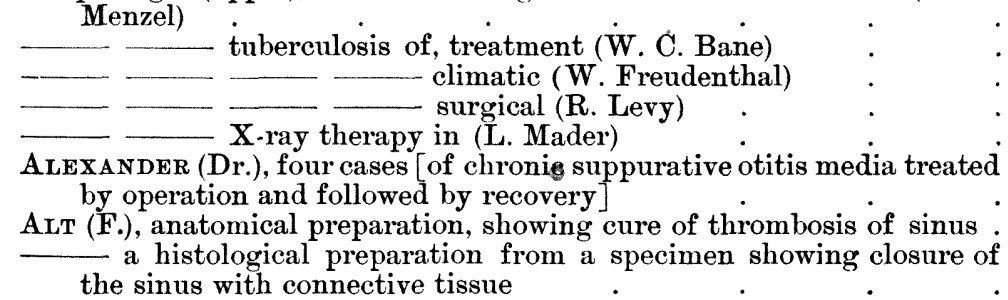

American Laryngological Association Congress : presidential address .

$=\frac{\text { proceedings }}{\text { Laryngological, Rhinological, and Otological Society; officers }}$ elected 1906 proceedings

Anæsthesia (artificial), radical mastoid operation performed painlessly without (Dr. Jaumenne)

(local) antrotomy and radical operations under (H. Neumann) . vapour method of (J. T. Gwathmey)

Anæsthetic, injection of solid paraffin into nose without (A. Wylie) 
Anæsthetics (administration of) for operations on nose and throat

$\begin{array}{ccc}\text { (A. de Prenderville, review) } & \text {. } & 308 \\ \text { Angeio-fibroma, microscopical section of (E. A. Peters) } & \cdot & .\end{array}$

Angeioma of auricle (H. E. Jones) $\quad . \quad$. $\quad . \quad 192$

(discrete) of septum (L. H. Pegler) . $\quad 202$

- (nasal) removed from floor of inferior meatus (W. R. Kelson) : 134

Antitoxin in treatment of diphtheria, nine years' experience (J. H.

McCollom). $\quad . \quad 2 \quad . \quad 10909$

Antrotomy and radical operations under local anæsthesia (H. Neumann) 402

Antrum (maxillary), empyema of ; symptoms (K. M. Menzel) . $\quad .209$

Aphonia (functional) following ague (E. A. Peters) . . . . 294

Armstrong (G. E.), carcinoma of the tongue $\quad . \quad . \quad 54$

Arthritis (infective) complicating otitis media (P. W. Eagleton) $\quad 167$

Aryepiglottic fold (left), swelling of (J. B. Ball) . . . 571

Arytenoid region (left), large sessile tumour in (H. W. Carson) $\quad$. 183

- (right), fixation of (H. J. Davis) $\quad \cdot \quad 184$

Asнвx (Henry), a discussion on congenital stridor (laryngeal and

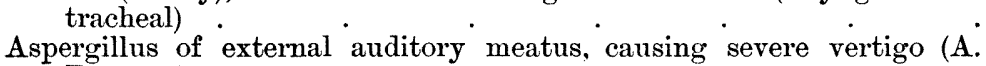

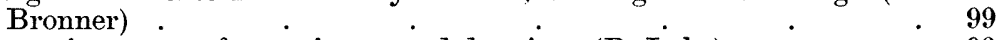

- niger, case of ; specimens and drawings (R. Lake) $\quad . \quad$. $\quad 99$

Atresia (congenital, complete osseous) of right nasal fossa (R. Botey) . 302

Attic, discharge from, with headache for eighteen months (E.

Urbantschitsch) . $\quad . \quad . \quad . \quad 223$

Auricle, angeioma of (H. E. Jones) $\quad . \quad 192$

\begin{tabular}{llll} 
Anst of (V. W. Wingrave) &. &. &. \\
\hline
\end{tabular}

- granuloma of (V. W. Wingrave) $\quad . \quad 191$

\begin{tabular}{llll}
- & $\cdot$ & $\cdot$ & 191 \\
\hline
\end{tabular}

removal of, for epithelioma of posterior surface (D. Mackenzie). 105

Auricles : indurated swelling of both auricles accompanying swelling
below anterior commissure of vocal cords (C. A. Parker).

Austrian Otological Society : proceedings . $\quad \cdot \quad$. 222, 289, 361

BABER (E. Cresswell), thimbles for making aseptic wool mops $\quad$. 572

BABITT (J. A.), the nasal turbinate as a vaso-motor index . . 338

BACON (Gorham), to what extent is it advisable to adopt conservative methods in the treatment of aural diseases? $\quad . \quad 4 \quad 469,483$

BALL (J. B.), case of ulceration of the pharynx and larynx $\quad$. $\quad 77$

- tumour of the pharynx . $\quad . \quad . \quad 570$

\begin{tabular}{llll}
- & $\cdot$ & & 570 \\
\hline
\end{tabular}

- papillomata in the nose . . . . . $\quad 572$

BALLENGER (William L.), presentation of instruments and apparatus . 334

$\begin{array}{ll}\text { discussion on treatment of deviation of nasal septum . } & 626 \\ \text { BANE (W. C.), treatment of [tuberculosis of] the upper air passages and } & \end{array}$ the ear . . . . . . . 340

BAR (Louis), mastoiditis without otorrhœa ; hearing recovered; cure $\quad \cdot 439$

BARANY (Dr.), theory of the function of the semicircular canals $\quad .361$

BARNHILI (J. F.), results of operation upon the nasal septum by means of various incisions .

BARR (J. Stoddart), case of otitic extra-dural abscess associated with paralysis of sixth cranial nerve and double otitic neuritis .

BARR (Thomas), valedictory address at Annual Meeting of Otological Society of the United Kingdom, December 4, $1905 \quad$. $\quad 46$

introductory paper to discussion on "Fixation of the Stapes" . $\quad 46$

Barwell (Harold S.), case of tuberculous ulceration of the nose, healed 37 case of lupus of the larynx and uvula, healed. $\quad 38$

case of tuberculous laryngitis ; removal of epiglottis ; cure $\quad \cdot 121$

case of tuberculous laryngitis; active local treatment; cure $\quad . \quad 122$

case of ulceration of epiglottis . 124

a case of lupus of the larynx, the palate, and the pharynx $\quad . \quad 188$ 
BARWELL (Harold S.), a case of infiltration of the left vocal cord

BAUMANN (Walther), the pharyngeal reflex . . 301

BAUMGarten (Egmont), acute affections of the eyes following acute nasal disease

BEck (Jos. C.), the submucous resection operation on the nasal septum

BECo (Dr.), naso-pharyngeal polypus ; extirpation ; death by collapse.

Belgian Society of Otology, Laryngology, and Rhinology : proceedings

BELLIN (L.), a case of dermoid cyst of the dorsum of the nose

and LEROUX (R.), congenital membranous occlusion of choanæ .

BerNstern (Edward J.), discussion on conservative methods in treatment of aural diseases

Birketr (H. S.), two cases of bony occlusion of the right posterior naris

BuAKE (C. J.), therapeutic effect of sound-waves
operations .

Buoch (Maurice), on the employment of borate of soda in ear cases

Blood-clot as primary dressing in mastoid operations (C. J. Blake) : - as dressing in acute suppurative inflammation of middle ear, with acute mastoiditis (F. L. Jack)

- (modified) in mastoid surgery (W. S. Bryant) $\quad$.

Blood-supply of inner ear (G. E. Shambaugh)

Blood-vessels in membranous labyrinth and the endosteum, and those in bony capsule of labyrinth, communications between (G. E. Shambaugh)

Boenninghaus (G.), on a peculiar condition of sensory irritability of the superior and inferior laryngeal nerves

Bond (J. W.), a case of palatal tumour of twenty years' duration

Bone impacted in larynx (J. M. Ingersoll)

Bony occlusion of right posterior naris (H. S. Birkett)

Borate of soda in ear cases (M. Bloch)

Bosviel (Dr.), a case of perichondritis of the thyroid cartilage

BOTEY (Ricardo), a case of congenital complete osseous atresia of the right nasal fossa

BouLAY (Dr.), exhibition of young girl aged seventeen who had recovered from diseased hip-joint and was affected with old-standing otorrhoa

BouRgueT (Julien), surgery of the labyrinth

Bouyer (Dr.), hyperæsthesia and paræsthesia of the pharynx.

Bôval (Dr.), radiograph of a coin lodged in osophagus of a child aged four, at the level of second dorsal vertebra - radiograph of a patient wearing a tracheotomy tube, and with a revolver bullet lodged in the left side of the neck

BRADY (A. J.), fibromata of the naso-pharynx and their removal by enucleation

Brain, abscess, cases of (S. Walker) 157, (P. Hammond) 2i1, (A. L. Whitehead) 349, (Dr. Trétrôp) - (hind), continuity of the fibres of auditory nerve with the auditory sense epithelium and with the nuclei in (J. Cameron and W. Milligan) . (H. Neumann)

British Laryngological, Rhinological, and Otological Association : proceedings . $\quad . \quad . \quad 15,100,160,186,297$

British Medical Association, Annual Meeting, Toronto, 1906, combined sections of Laryngology and Pediatrics : proceedings . . 441 section of Laryngology and Otology .

$\overline{\text { BROECKAERT }}$ (Dr.), ozæna cured by submucous injectio. $45 \dot{7}-511,5 \dot{13}, 517$

BroEcKaERT (Dr.), ozæna cured by submucous injections of paraffin $\quad$. 396 case of pseudo-leukæmia simulating so-called Mikulicz's disease. 434 
Broeckaert (Dr.), normal and pathological inclusion of soft and hard paraffin in the tissues presentation of instruments
the etiology of ozæna

Bronchoscopy (direct), new instruments for removal of foreign bodies from bronchi by (W. C. Morton)

Bronchus, foreign body extracted from, by tracheotomy (Dr. van Swieten)

BroNNER (Adolph), notes on a case of severe vertigo, due to aspergillus of the external auditory meatus

BRYAN (J. H.), malignant disease of tongue

BRYANT (Alice G.), the use of the cold wire snare in the removal of hypertrophied tonsils

BRYANT (W.S.), obstruction of the Eustachian tube and its treatment . 166

- modified blood-clot in mastoid surgery . . . . 339

Buccal pouch, lipoma of, congenital (V. W. Wingrave) $\quad . \quad 523$

Bullet (revolver) in left side of neck (Dr. Bôval) . . . . 392

BuletTe (W.), a case of epileptiform hysteria, probable result of necrosing ethmoiditis

Calculi of unusual size from Wharton's duct (Koenig)

Calomel (injections of) in syphilitic ulceration in pharynx (j. Dundas Grant)

Cameron (John) and Milligan (William), the mode of continuity of the fibres of the auditory nerve with the anditory sense epithelium, and with the nuclei in the hind brain

Cancer (inoperable) of fauces treated with a bacterial vaccine of Micrococcus neoformans (S. Spicer)

Cannula, laryngotomy performed without ( $\dot{\mathrm{A}}$. Castex)

- (tracheal) worn for nearly twenty-seven years on account of incomplete bilateral paralysis of posterior crico-arytenoid muscles (Sir F. Semon)

CAPART (A.), diverticulum of the entrance of the csophagus :

CAPART (A.), diverticulum of the entrance of the cesophagus :

the indications for operation in the treatment of sinusitis

Carbonic-acid gas at Spa in treatment of affections of throat, nose, ears, and eyes (E. Delneuville)

Carcinoma, total resection of superior maxilla for (Dr. Goris) .

Carson (H. W.), large sessile tumour in left arytenoid region . a man with an ulcerated swelling in the middle line of the nasopharynx, and ulceration of the left posterior fold of the palate

Cartilage, piece of, impacted in pyriform fossa (R. Landesberg)
CASSELBERRY (W. E.), a discussion on laryngeal disturbances produced by voice use. Introductory paper $\quad . \quad$. $\quad . \quad 528,536$

CASTEX (A.), laryngotomy without cannula.

CATHCART (G. C.), a case of tertiary syphilis of the larynx : $\quad . \quad 44$ - report on Dr. E. Law's case of incrustations in trachea terminating fatally

CAUTLEY (E.), discussion on congenital stridor, laryngeal and tracheal .

Cerebellum, abscess of (A. L. Whitehead) 63, 146, 348, (D. Grant) 113, (H. Neumann)

Cervical glands : cancer (inoperable) of fauces, pharynx, tongue, and cervical glands; amelioration after treatment with bacterial vaccine

of neoformans (R. H. Scanes Spicer and Sir A. E. Wright)
Cheatle (Arthur H.), the prevention of ear affections due to exposure to loud noises and to explosives

Cheek, nævus of (M. Collier) :

Children, laryngeal papillomata in; treatment by operation (D. R. Paterson) . 
Chin, sinus of (W. H. Kelson)

Chisholm (W. A.), skiagraphy in diagnosis of frontal sinusitis

Choana (right), absence of (E. B. Waggett) .

Choanæ, congenital membranous occlusion of (L. Bellin and R. Leroux) mucous polypi of, origin (G. Killian)

Cholesteatomatous lining, retention in operation for acute mastoiditis (W. Stuart-Low)

Circulation in labyrinth of ear (G. E. Shambaugh)

Circulatory disturbances following ligation of internal jugular vein in sinus thrombosis (W. P. Eagleton)

Cleft palate, case showing that adenoids diminish the dyslalia (W. Stuart-Low)

Climatic treatment of tuberculosis of upper air-tract (W. Freudenthal)

Coakley (Cornelius G.), nasal skiagraphy .

skiagraphy as an aid in the diagnosis and treatment of diseases of the accessory sinuses of the nose

Cochlea, partial necrosis of, and sigmoid sinus thrombosis (H. S. Walker)

CoFFIN (Rockwell), a new gouge for submucous operations in the nose

Coin lodged in osophagus at level of second dorsal vertebræ (Dr. Bôval)

CoLlET (Dr.), a series of patients operated upon by evacuation of the ethmoid from the nostril

Collier (Mayo), a case of syphilitic disease of larynx

- case of nævus of the cheek

Connective-tissue, closure of sinus by (F. Ait)

Coolidae (A., jun.), a foreign body in the œesophagus

Cranium (human, embryonic), models of (O. Grosser) (osteomyelitis of, diffused), following acute frontal sinusitis of staphylococcic origin (Luc)

Crico-arytenoid joint (right), fixation of, due to infiltration (E. F.

Potter) muscles, posterior; incomplete bilateral paralysis of $(\operatorname{Sir} \mathbf{F}$. Semon)

Crockett (E. A.), a case of acute meningitis; operation; recovery

Cumberbatch (A. E.), presidential address (Otological Society of the United Kingdom)

discussion on fixation of the stapes .

Cyst (air-containing), connected with left ventricle of Morgagni (Dr. Labarre) .

D'Aivtolo (G.), a very simple and efficacious aural masseur (abstract) . 111

DAvis (H. J.), case of atrophic rhinitis .. .125

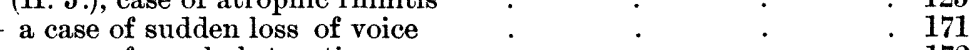

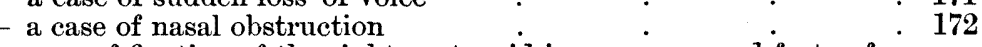

case of fixation of the right arytenoid in a woman aged forty ; for diagnosis (shown for Dr. E. F. Potter) . . . . 184

three cases of syphilis in one family, (?) oral infection $: \quad .227$

- case of stenosis of the larynx $\quad . \quad 5756$

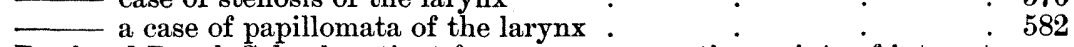

Deaf and Dumb School, patient from ; case presenting points of interest

(Dr. v. Hammerschlag)
Deafness : pathological conditions found in subject of deafness during life (A. A. Gray) (progressive), influence of pregnancy and parturition on certain forms of (W. Milligan) 280

Delavan (D. Bryson), the ultimate results of radical operations upon

the accessory nasal sinuses
DELNEUvILLE (E.), the treatment of affections of the throat, the nose,
the ears, and the eyes by carbonic acid gas at Spa the ears, and the eyes by carbonic acid gas at Spa $\quad . \quad 167$

- a case of sphenoidal sinusitis with ocular complication $\quad . \quad 263$ 
Delsaux (Charles Emile), microscopic sections-tuberculosis of the septum and lupus of the nose.

DeLsaUX (V.), stereoscopic photographs of Killian's rhino-phantom subperiosteal abscess of the forehead complicated with thrombophlebitis of the superior longitudinal sinus

Delstanche (E.), mastoiditis and furunculosis

- the treatment of othæmatoma

DENKER (Alfred), a new mode of access in the operation for nasal malignant tumours .

Dental saliva-ejector as a surgical instrument (R. H. Woods) . . $\quad 61,162$

Denture removed by cosophagotomy (W. Downie) . . $\quad . \quad 129$

Dermoid cyst of dorsum of nose (L. Bellin). $\quad . \quad 1 . \quad . \quad 285$

- of neck (V. W. Wingrave) . $\quad . \quad . \quad 23$

Digestive tract, leukæmic changes in (K. M. Menzel) $\quad$. $\quad .437$

Diphtheria, treatment by antitoxin, nine years' experience (J. H. McCollom)

DIXoN (G. Sloan), report of a case of panotitis resulting in meningitis 166

DonELAN (J.), chronic thickening and deformity of epiglottis and rocal cords of four year's duration in a girl aged sixteen ; for diagnosis . - case of laryngeal ulceration in a man aged fifty-four. - a woman aged twenty-four with a swelling on the upper part of the septum nasi ; for diagnosis

Donovan (John A.), discussion on cold wire snare in removal of hypertrophied tonsils

Downit (Walker), photographs of some cases of paraffin injection for nasal deformity

description of two cases where cesophagotomy was performed for removal of a denture impacted in the gullet

Dressings, methods for carrying and keeping aseptic (Prof. Pollak) . 226

Dupux (Homer), acute affections of the pharyngeal tonsil in early life 202

Dura of posterior fossa displaced inwards; sinus compressed by neoplasm (H. Neumann)

Dyslalia, diminution of, by adenoids, shown in case of cleft palate $(W$. Stuart-Low)

Dysphagia, case of (W. Chichele Nourse) for liquids in case of fixation of right vocal cord (W. Stuart-Low)

Dysphonia, without tubercular or other lesions (Koenig)

Dyspncea due to swelling below anterior commissure of vocal cords (C. A. Parker)

Eagleton (P. Wells), infective arthritis complicating otitis media (abstract) .

- circulatory disturbances following ligation of the internal jugular vein in sinus thrombosis

Ear, circulation in labyrinth of (G. E. Shambaugh) . (diseases), pathogenic influence of aural lesions in systemic disease (S. MacCuen Smith) statistical report of department of oto-rhino-laryngology at Hospital Saint-Jean, Brussels (A. Fallas) treated by carbonic acid gas at Spa (E. Delneuville) 
Ear (middle, disease of) inflammation, acute suppurative, with acute mastoiditis, blod-clot dressing in (F. L. Jack) suppuration of, acute, complicated by labyrinthine fistula and paralysis of the abducens nerve ( $H$. Hastings) as a cause of retropharyngeal abscess (E. M. dangerous sequelæ of ( $\mathrm{J}$. Dundas Grant)

Electro-cautery, in treatment (R. Levy) -

Electrolysis in treatment of chronic Eustachian stenosis (F.T. Hopkins) 363

Elevators, newly-designed, exhibition of (R. H. Woods) . 301

ELLIS (H. Bert), infective sigmoid sinus thrombosis; resection of internal jugular, report of a case, recovery

Empyema (frontal, chronic), four cases operated on by simplified Killian

operation (H. Tilley). Scanes Spicer)

Encephalocele (fronto-nasal) (F. E. Hopkins)

Endosteum, blood-vessels in, and in membranous labyrinth, communicating with those in bony capsule of labyrinth (G. E. Shambaugh) .

Endothelioma of pharynx (V. W. Wingrave)

Epiglottis : chronic thickening and deformity of epiglottis and vocal cords (J. Donelan).

- deformity of, accompanying swelling below anterior commissure of vocal cords (C. A. Parker).

- tuberculosis of soft palate, pharynx and epiglottis (C. Fox)

ulceration (V. W. Wingrave) 17 , (H. Barwell)

Epithelioma : villous papillomatous growths in larynx, probably epi-

thelioma ( $J$. Dundas Grant)
Epithelium (auditory sense), mode of continuity of fibres of auditory
nerve with (J. Cameron and W. Milligan)

Escat (Dr.), indications for the use of the galvano-cautery in the various forms of laryngeal tuberculosis and its value. . .

Ether narcosis by rectum (J, A. Stucky) . $\quad . \quad$. $\quad .341$

Ethmoid, evacuation of, from nostril (Dr. Collet) $\quad \cdot \quad \cdot \quad \cdot \quad \cdot 395$ - and superior maxilla, osteomyelitis of, with suppuration in sinuses and in orbit (Dr. van der Wildenberg).

Ethmoiditis (necrosing) probable cause of epileptiform hysteria (W. Bulette) . . (F. L. Jack)

Ethmo-turbinal cells, clinically considered (J. O. Roe) $\quad . \quad$. $\quad .326$

Eustachian cartilages, great enlargement of (W. Stuart-Low) : $\quad .186$

\begin{tabular}{lll} 
Eustachian cartiages, & 186 \\
\hline
\end{tabular} tube, electrolysis in chronic stenosis of (F. T. Hopkins) : 363

obstruction of, with treatment (W. S. Bryant) $\quad 166$

Explosives, prevention of ear affections due to exposure to (A. H. Cheatle) 48

Eye, diseases of, treated by carbonic acid gas at Spa (E. Delneuville) . 167 (acute), following acute nasal disease (E. Baumgarten) : 400 ocular complication of sphenoidal sinusitis (E. Delneuville), 263 
Face, tumour of left half of, originating in roof of pharynx (K. Jager) Fallas (A.), some cases of laryngeal stenosis . 397, 398 - statistical report of the department of oto-rhino-laryngology at the Hospital Saint-Jean at Brussels

a case of laryngeal stenosis (abstract)
Fauces, cancer (inoperable) of fauces, pharynx, tongue, and cervical glands; amelioration after treatment with bacterial vaccine of neoformans (R. H. Scanes Spicer and Sir. A. C. Wright) . 265, infection through (septic) (G. A. Leland) . .

- (systemic) (J. N. Goodale) $\quad \cdot \quad \cdot \quad \cdot \quad \cdot \quad 582$

Faucial pillar (right), new growth (P sarcoma) in region of right tonsil and anterior faucial pillar (P. H. Abercrombie)

Ferrert (G.), a contribution to the treatment of laryngeal tumours Fibro-angeioma of nasal septum (H. B. Robinson)

Fibro-sarcoma arising from the thyro-hyoid membrane (K. Renshaw)

FIocRe (Dr.), a case of primary hæmorrhage from the naso-pharynx

Fish-hook removed from œsophagus (D. R. Paterson)

Fistula between mouth and nose, closure of (Luc)

Flames, inhalation of, causing papilloma of larynx (A. B. Thrasher)

Forceps (Lubet-Barbon's) used in operation for voluminous naso-pharyngeal polypus (Lubet-Barbon)

newly-designed, exhibition of (R. H. Woods).

Foreign bodies and tracheoscopy (A. Coolidge, jun.) .

(Dr. van Swieten)

(Koenig) .

in auditory meatus resembling fibrous polypus

-1 in larynx, rare case (N. Zia)
(H. Neumayer) cesophagoscope in diagnosis and treatment of
bronchoscopy (W. C. Morton)

Formawn

Fonstelles (Arthur), on the resection of the inferior turbinal bone

Fossa (nasal, right), congenital complete osseous atresia of (R. Botey) (posterior), displacement of dura inwards, and compression of sinus by neoplasm (H. Neumann)

Foster (E. E.), description of Killian's frontal sinus operation (abstract)

Fox (Clayton), a case of tuberculosis of the soft palate, the pharynx, and the epiglottis

Freer (Otto T.), the removal of adenoid vegetations through the nasai passages by a new method the problem of the correction of deflections of the nasal septum solved by the submucous resection

Freddenthat (Wolff), the climatic treatment of tuberculosis of the upper air-tract

Frey (Hugo), the anatomy of the temporal bone
Frontal bone, osteitis of (chronic), with chronic sinusitis (E. A. Peters) sinus (R. H. Scanes Spicer) sinus, inflammation of (H. P. Mosher)

Killian's operation on (E. E. Foster) . - (bilateral) (StC. Thomson) suppuration of, unusual cases (P. G. Goldsmith) (left) suppuration of left frontal and left maxillary sinuses, closure of wound and irrigation (C. J. Symonds) (right), empyema of, with subacute osteomyelitis of frontal bone (R. H. Scanes Spicer) 
Frontal sinuses, sarcoma of, further notes on case previously exhibited twice (P. H. Abercrombie) suppuration in, treated by intra-nasal methods $(\dot{J}$. Dundas Grant) treated by irrigation only (C. J. Symonds)

Fruit pastilles, laxative (tabloid).

Furet (Dr.), a woman aged forty, with syphilis in naso-pharynx $\quad \cdot 287$

Furunculosis : diagnosis from mastoiditis (E. Delstanche) $\cdot{ }^{\circ} \quad 264$

Galvano-cautery in laryngeal tuberculosis (Dr. Escat) . . . . 433

Gavazzeni (S.) and Limonta (G.), the treatment of Ménière's disease . 111

Gavello (G.), on the laryngeal disturbances in syringomyelia $\quad 110$

the paralyses of the vocal cords in mitral affections . $\quad .110$

$\begin{array}{lllll}\text { Glaseptic nebuliser } & \text {. } & . & . & 168\end{array}$

Glass, syringe for intra-tracheal injections made entirely of (Koenig) . $\quad 285$

Greitsman (Joseph W.), presidential address, American Laryngological Association

Glosso-epiglottidean lympho-sarcoma (J. Dundas Grant) $\quad$ • $\quad$ • $\quad 580$

Glottis, stenosis of (StC. Thomson) $\quad . \quad 176$ requiring tracheotomy, caused by complete healing of extensive tuberculous laryngitis (StC. Thomson) $\quad . \quad 573$

Goitre (exophthalmic), medical treatment of (R. D. Rudolf) : $\quad$. $\quad 55$

Goldsmith (Perry E.), inflammation of the nasal mucous membrane 55 - some unusual cases of frontal sinus suppuration.$\quad 484$

GoLDstern (M. A.), the treatment of perforations of nasal septum 337

GOODALE (J.L.), examination of the throat in chronic systemic infections 386 systemic infection through fauces.

Gordon (A. Knyvett), some further experiences of the operative treatment of scarlatinal otitis

some further experience of the radical mastoid operation in scarlatinal otitis

Goris (Dr.), disturbances of the recurrent nerves following thyroidectomy total resection of the superior maxilla for carcinoma.

Gouge (new) for submucous operations in nose (R. Coffin)

Granuloma of auricle (V. W. Wingrave)

Grant (J. Dundas), case of swelling over the left superior maxilla in a middle-aged woman (formerly shown).

the dangerous sequelæ of middle-ear suppuration $\quad \cdot$

case of ulceration of the pharynx (probably specific) presenting unusual features - extensive syphilitic ulceration in the pharynx of a man aged twenty-eight, treated by calomel injections; rapid improvement . - Sondermann's suction apparatus case of suppuration in both frontal sinuses treated by intra-nasal methods case of injection of cold paraffin for nasal deformity .

a case of thrombo-phlebitis of jugular bulb and cerebellar abscess; ligature of vein, later evacuation of sinus and bulb, drainage of cerebellar abscess, recovery.

case of lateral sinus thrombosis treated by operation without ligature of jugular vein ; recovery case of infiltration, with fixation, of the right vocal cor $\dot{d}$ in a man aged forty-six villous papillomatous growth, probably epithelioma growth, shown by Dr. Wyatt Wingrave

case of epithelioma of the palate in a male patient aged sixty - address on some practical problems in otology and rhinology.

- introductory remarks at Annual Meeting of British Medical Association, Section of Laryngology and Otology (1906) . 
Grant (J. Dundas) and Nourse (W. Chichele), retrospect of otology, 1905

Gray (Albert A.), the pathological conditions found in the case of an individual who had suffered from deafness during life (abstract)

demonstration illustrating pathological conditions found in the human labyrinth - demonstration illustrating the comparative anatomy of the labyrinth of the mammalia

- introductory paper to discussion on fixation of the stapes - observations on the labyrinth of certain animals

Green (D. Crosby), a study of the larynx in tabes. subcutaneous correction of a Roman nose

GRosser (Otto), models of the human embryonic skull

GUISEz : concerning paraffin endonasally as supplementary treatment of sinusites.

Gullet: see Esophagus.

GWAтнмкY (James T.), the vapour method of anæsthesia (abstract)

Gynæcological operation curing case of Ménière's symptom-complex (E. Urbantschitsch) .

Hæmatoma of right ear in Swiss wrestlers (Valentin)

Hæmorrhage from tonsil during morcellement (Heckel)

(primary), from naso-pharynx (Fiocre)

HALSTED (T. H.), mixed tumour of the soft palate

HamaIDe (Dr.), stenosis of the larynx consecutive to intubation

von HAMmErschlag (Dr.), a pupil of the Deaf and Dumb School whose case presented some points of interest.

Hammond (P.), brain abscess ; operation ; recovery (abstract).

Harris (Thomas J.), fibroma of the larynx in a child aged five; apparent cure; recurrence as a papilloma ; laryngo-fissure; cure

Hastings (Hill), a case of acute middle-ear suppuration complicated by labyrinthine fistula and paralysis of the abducens nerve (abstract) .

ocular symptoms of nasal origin

Headache: pathological conditions of middle turbinal a causal factor (H. Smurthwaite) - (persistent, unilateral) due to nævoid changes in the anterior extremity of the middle turbinal bone (V. W. Wingrave) . with discharge from attic (E. Urbantschitsch)

Hearing (defective) from childhood; considerable recovery (H. S.

Walker) organ of, histo-pathological examination of ( $\dot{W}$ ittmaarck) - (organs of) in lower animals (L. Miall)

Heckel (Dr.), exhibition of patient in whom severe hæmorrhage from the tonsil took place during morcellement

HeINE (B.), isoform in the after-treatment of the radical operation (abstract).

HenRICI on tuberculosis of the mastoid in childhood the indications for "curative" tracheotomy in laryngeal tuberculosis

Herpes zoster auris (D. T. Vail) .

PAGE

HrLL (William), recent nasal polypus and sinusitis in a patient with long-standing atrophic rhinitis

Hip-joint (disease of), case of recovery from, old-standing otorrhœa persisting (Boulay) .

Hrtz (H. B.), double mastoiditis complicated by an intercommunicating suboccipital abscess .

HoLmes (Edgar M.), middle-ear suppuration as a cause of retropharyn-

geal abscess
Hopkins (Frederic E.), fronto-nasal encephalocele 
Hopkins ,F. T.), electrolysis in the treatment of chronic Eustachian stenosis (abstract)

Horne (W. Jobson), a point in the differential diagnosis of excrescences

in the interarytenoid space .
report on Dr. E. Law's case of incrustations in trachea, terminating fatally

HUBBARD (Thomas), cases of sarcoma

Hunt (J. Middlemass), a discussion on laryngeal disturbances produced by voice use. Introductory paper . $\quad . \quad 519,536$

Hyperæsthesia of pharynx (Dr. Bouyer) . . . . 435

Hyperkeratosis of tonsils, etiology of (G. B. Wood) . $\quad$. $\quad .387$

Hysteria (epileptiform), probable result of necrosing ethmoiditis (W. Bulette) .

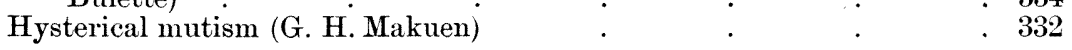

Incrustations in trachea, fatal termination of case (E. Law, G. C. Cathcart and W. Jobson Horne) . . . . . . 44,45

Infection (septic) through fauces (G. A. Leland) $\quad . \quad . \quad . \quad 583$ (systemic) through fauces (J. N. Goodale) $\quad . \quad 5 \quad . \quad 582$

Infections (systemic, chronic), examination of throat in (J. L. Goodale) . 387

INGERsol. (J. M.), the function of the accessory cavities of the nose.$\quad 337$

$\begin{array}{ll}\text { two cases of bone impacted in the larynx } . & 382\end{array}$

Instruments, presentation of (Dr. Broeckaert, Dr. Trétrôp) $\quad . \quad . \quad 393$

$\begin{array}{llll}\text { (new) for removal of foreign bodies from bronchi by direct } & \\ \text { bronchoscopy (W. C. Morton) } & . & \text {. } & 12\end{array}$

- (small) methods for carrying and keeping aseptic (Prof. Pollak) 226

$\longrightarrow$ and apparatus, presentation of (W. L. Ballenger) . 334

Interary tenoid fold, tumour in, probably tuberculous (Sir F. Semon) : 31 space, excrescences in : point in differential diagnosis of (W. Jobson Horne) . . . . . . 33

International Laryngo-Rhinological Congress (1908) $\quad . \quad 107$

Intra-nasal methods in treatment of suppuration in both frontal sinuses (J. Dundas Grant) . . . . . . 74, 82

Intra-tracheal injections, syringe for, made entirely of glass (Koenig) : 285

Intubation in laryngeal stenosis, necessity for early use (E. W. Saunders) 264 - stenosis of larynx consecutive to (Dr. Hamaide) . $\quad .393$

Iodides, in treatment of tertiary syphilis of nose (Dr. Mahu) $\quad . \quad 4 \quad 432$

Irrigation in treatment of suppuration of left frontal and left maxillary sinuses (C. J. Symonds)

only, in treatment of suppuration of frontal sinuses (C. $\dot{J}^{*}$ Symonds).

Isoform in the after-treatment of radical operation (B. Heine)

Italian Laryngological, Otological, and Rhinological Society, date of tenth Congress (1905)

JACK (F. L.), report of four cases showing the results of Killian's operation the blood-clot dressing

Jacksos (Chevalier) . 584

JAckson (Chevalier) submucous resection of the nasal septum . 336

thyrotomy and laryngectomy for malignant disease of larynx 632,651

JACOBI (A.), the tonsil as a portal of microbic and toxic invasion (abstract) .

JAGER (Karl), tumour of the left half of the face originating in the roof of the pharynx

JAUMENne (Dr.), a case of radical mastoid operation performed pain.

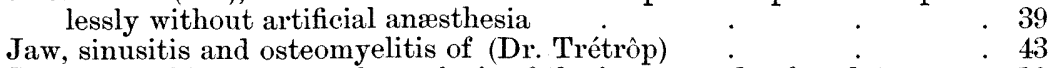

Jones (Buckland), case of paralysis of the larynx and soft palate $\quad . \quad 103$

Jones (Hugh E.), angeioma of the auricle (with photographs, macro. scopic and microscopic specimens and plaster casts from a case) $\quad$. 192 
Jones (Buckland), some complications of suppurative disease of the middle ear .

introductory paper to a discussion on the indications for the

ligation of the internal jugular vein in otitic pyæmia.

Jugular vein, internal; ligation in otitic pyæmia (H. E. Jones) (J. F. Mc.Kernon).
ligation of, in sinus thrombosis, followed by cir: culatory disturbances (W. P. Eagleton)

Ellis)

KeLLY (A. Brown), sclerotic hyperplasia of the pharynx and nasopharynx

- sketch of larynx and microscopic section of uvula from case of hyperplastic congenital syphilis

Kelson (W. H.), a case of sinus of the chin

a case of ulceration of the left vocal cord .

a pedunculated growth of urula in a man aged nineteen

- case of chronic inflammation of the external auditory meatus on

both sides, with marked stenosis

microscopic section from a case of nasal angeioma (bleeding

polypus) removed from floor of inferior meatus in a girl aged fifteen

- a case of ulceration of the left cord.

case of laryngeal disease.

- a case of ulceration (? malignant disease) of the base of the tongue

KILLIAN (G.), origin of mucous polypi of the choanæ (abstract) .

Killian's operation in chronic suppurative ethmoiditis ; result in four cases (F. L. Jack) .

Jack)

(bimplified) in treatment of four cases of chronic frontal empyema

(H. Tilley)

Killian's rhino-phantom, stereoscopic photographs of (V. Delsaux)

KING (Gordon), a voluminous papilloma of nasal cavity

KIRKPATRICK (A. B.), the subcutaneous injection of paraffin for nasal and other deformities and the submucous injection for atrophic rhinitis

KNAPP (Arnold), serous meningitis

Koenig (Dr.), exhibition of (1) a syringe for intra-tracheal injections made entirely of glass; (2) an unusual foreign body of the auditory meatus, resembling a fibrous polypus; (3) two calculi of unusual size from Wharton's duct

exhibition of (1) a man aged fifty, with dysphonia without tubercular or other lesions; (2) a woman aged forty with a cold abscess of the left false cord

KopLIK $(\mathrm{H}$.), congenital laryngeal stridor, a contribution to the pathology of the affection, with report of an autopsy on a case .

Koplik spots: relation and interest to laryngologists (H. G. Langworthy)

KUTTNER (A.), critical observations on the present position of the " recurrent" question

LABARRE (Dr.), laryngocele of the ventricle; an air-containing cyst connected with the left ventricle of Morgagni

Labyrinth, circulation in (G. E. Shambaugh)

(fistula of) complicating acute middle-ear suppuration $(\mathbf{H}$.

Hastings).

PAGE 
Labyrinth (human), demonstration of pathological conditions in (A. A. Gray)

- (membranous), blood-vessels in, and in endosteum, communicat-

ing with those in bony capsule of labyrinth (G. E. Shambaugh) .166

- _ of certain animals (A. A. Gray) . . . . . 365

- of mammalia, comparative anatomy of (A. A. Gray) . . . 142

— suppuration of; histological preparation (A. Politzer) . $\quad 222$

surgery of (J. Borguet)
Labyrinthitis (suppurative), clinical and anatomo-pathological study of case (P. Laurens)

LAKE (Richard), skulls showing the different stages of an operation for opening the vestibule specimens and drawings of a case of aspergillus niger . fixation of stapes.

LANDESBERa (Rudolf), a piece of cartilage impacted in the pyriform fossa

LANGMAID (S. W.), the effects of tobacco upon the throat

LANGWORTHY (H. Glover), a case of primary erysipelas of the pharynx Koplik spots; their relation and interest to laryngologists

Laryngectomy in treatment of malignant disease of larynx (C. Jackson)

(partial), lymphoid tumour of larynx removed by (G. King) :

Laryngitis (tubercular), treatment of cases in public sanatoria (G. L. Richards)

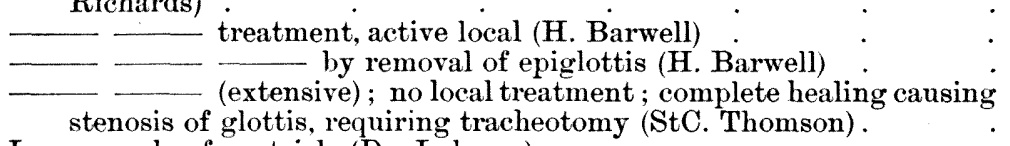

Laryngocele of ventricle (Dr. Labarre)
Laryngo-fissure for recurrence of fibroma of larynx as papilloma (T. J.

Harris) . .331

Laryngological Society of London, annual meeting and dinner $\quad .107$

- officers and members of Council for Session 1906-1907 283

- proceedings $31,35,69,79,149,171,227,292,570$

- report of Morbid Growths Committee 35, 292

Laryngologists, relation and interest of Koplik spots to (H. G. Langworthy)

Laryngology, retrospect of 1905 (J. Macintyre)

Laryngotomy performed without cannula (A. Castex)

Larynx, angejoma of (V. W. Wingrave)

bone impacted in (J. M. Ingersoll) .

congenital laryngeal stridor (H. Koplik)

(disease of) case of (W. H. Kelson)

- laryngeal disturbances produced by voice use (J. Middlemass Hunt), 519; (W. E. Casselberry) .

statistical report of department of oto-rhino-laryngo-

logy at Hospital Saint-Jean, Brussels (A. Fallas)

Wepithelioma of (V. W. Wingrave) 191, (Dr. Schiffers) 396, P.

Watson Williams) . fibroma of, recurrence as papilloma treated by laryngo-fissure

(T. J. Harris) foreign body in rare case of (N. Zia) growths of, innocent: pathology of 50 cases (V. W. Wingrave) 215 in tabes (D. C. Green) . $\quad$. . . 209

lupus of larynx, palate, and pharynx (H. Barwell) $\quad \cdot \quad \cdot \quad 188$

lymphoid tumour of, removed by partial laryngectomy (G. King) 209 malignant disease, treatment by laryngectomy (C. Jackson) $\quad 632$ $\begin{array}{ll}\text { (right side) in a syphilitic man (StC. Thomson) } & : 580 \\ \text { treatment by thyrotomy (C. Jackson). } & .632\end{array}$ neoplasm of (W. Chichele Nourse). 
Larynx, neoplasm, intrinsic; case previously shown (R. H. Scanes Spicer)

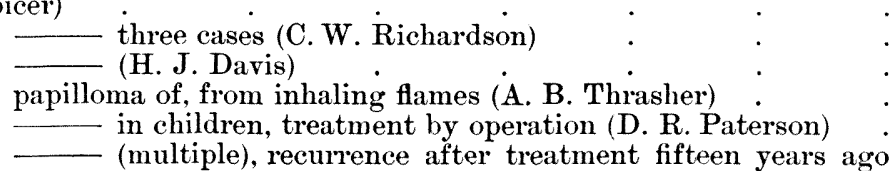

(R. H. Scanes Spicer) paralysis of larynx and soft palate (B. Jones) pharyngo-laryngeal unilateral (Avellis' syndrome) (C.Poli)

association with paralysis of other muscles on same

side (C. Poli) scleroma of (E. Mayer) section of, from case of hyperplastic congenital syphilis

(A. Brown Kelly) stenosis of (A. Fallas) 397, 398, 653, (H. J. Davis)

consecutive to intubation (Dr. Hamaide)

- following subglottic abscess (A. Fallas)

necessity for early use of intubation in (E. W. Saunders) with paralysis of left vocal cord (A. Fallas)

syphilis of, tertiary (G. C. Catheart)

syphilitic disease of (M. Collier)

granulomata and stenosis : thyrotomy (H. S. Barwell) ? tuberculosis of, indications for "curative" tracheotomy in

(Henrici)

bilateral, healed without local treatment (StC. Thomson) galvano-cautery in (Dr. Escat)

(tumours of), treatment (G. Ferreri)

ulceration of ( $\mathrm{J}$. Donelan) .

villous papillomatous growth, probably epithelioma $(\dot{\mathrm{J}}$. Dundas

Grant) - preparations illustrating cases (V. W. Wingrave) and uvula, lupus of (H. S. Barwell)

Lateral sinus, latent thrombosis of (Dr. van den Wildenberg) .

LAURENs (Paul), a clinical and anatomo-pathological study of a case of suppurative labyrinthitis

LAw (Edward), report on the fatal termination of the case of incrustations in the trachea, with at times well-marked stenosis; shown by Dr. Edward Law at the meetings of the Society on November 4 and December 2, 1904, and March 17, 1905 (with reports by Drs. G. C. Cathcart and Jobson Horne)

LAWRENCE (L. A.), a case of almost complete occlusion of the meatus, the result of an accident

LECOCQ (Dr.), gigantic polypus removed from a female aged sixty

LELAND (G. A.), septic infection through fances . choanæ

LEVY (Robert), surgical treatment of tuberculosis of the upper airpassages and the ear

Leukæmia of mucous membrane of upper air-passages and digestive tract (K. M. Menzel)

"Lichenoids" (V. W. Wingrave)

Limonta (G.) and Gavazzeni (S.), the treatment of Ménière's disease

LiNCOLN (William), mouth-breathing

Lip (upper), lymphangitis of (A. Wylie)

Lipoma of buccal pouch (congenital) (V. W. Wingrave)

Liquids, dysphagia for, in case of fixation of right vocal cord (W. Stuart. Low)

Lobule (auricular), ulceration of ( $\dot{W}$. Stuart-Low) 
Loes (Hanau W.), a study of the anatomy of the accessory sinuses of the nose, based upon reconstructions of two head

LOGAN (James E) endothelioma of the throat; tonsillar disease ${ }^{\prime} \cdot$

presidential address at Kansas City

Longitudinal sinus (superior), thrombo-phlebitis of ( $\dot{\mathrm{V}}$. Delsaux)

Love (J. Kerr), stereograms illustrating five cases of the radical mastoid operation, and one of a polypus attached to a diseased malleus .

LUBET-BARBON (Dr.), a patient who had been operated on recently for a voluminous naso-pharyngeal polypus by means of the author's forceps

Luc (Dr.), exhibition of (1) a patient who was cured of diffused osteomyelitis of the cranium following an acute frontal sinusitis of staphylococcic origin, complicated with extra- and intra-dural abscess; (2) a complicated deviation of the nasal septum ; (3) a case of closure of fistula between mouth and nose. .

Lymphangitis of upper lip (A. Wylie)

Lymphoid tonsillar circle (G. Wishart)

Lympho-sarcoma, glosso-epiglottidean (J. Dundas Grant)

PAGR

McCollom (J.H.), the experience of nine years in the treatment of diphtheria with antitoxin

McDonagh (George R.), a discussion on the treatment of deviations of the nasal septum ; introductory paper .

Macfarlane (Murray), discussion on pathogenic influence of aural lesions in systemic disease

Macintyre (John), retrospect of laryngology, 1905 .

MACKENZIE (Dan) : auricle removed for epithelioma of posterior surface with microscopic sections (prepared by Dr. Wyatt Wingrave) . - case of epithelioma of posterior surface of auricle

McKernon (J. F.), introductory paper to a discussion on the indications for the ligation of the internal jugular vein in otitic pyæmia.

MADER (L.), on X-ray therapy in upper air-passages .

MAHU (Dr.): the efficiency of treatment of tertiary syphilis of the nose by iodides.

MakUen (G. Hudson), hysterical mutism

two cases of stammering, illustrating the importance of early treatment .

discussion on congenital stridor, laryngeal and tracheal discussion on laryngeal disturbances produced by voice use

Malignant disease : infiltration, probably malignant disease, causing fixation of right crico-arytenoid joint (E. F. Potter) $\quad 85$

Malignant growth, originating in skin over mastoid process (W. Milligan) 145

Malleus (diseased), polypus attached to (J. K. Love) .99

- (handle of), necrosis of (P. Macleod Yearsley) $\quad . \quad 9.93$

Mammalia, labyrinth of, comparative anatomy of (A. A. Gray) $\quad .142$

Masseur (aural), simple and efficacious (G. D'Aiutolo) ? . 111

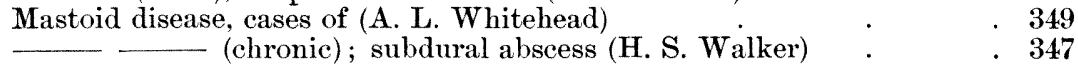
tuberculosis in, in childhood (Henrici) $\quad: \quad 401$ operation (radical), isoform in after-treatment of (B. Heine) : 402

(Dr. Jaumenne) Pe. 396

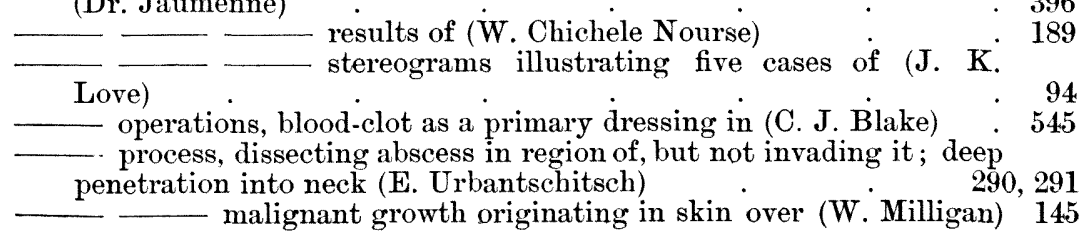


Mastoid surgery, modified blood-clot in (W. S. Bryant) . . 339

Mastoiditis : diagnosis from furunculosis (E. Delstanche) . . 264 and temporo-sphenoidal abscess (S. Oppenheimer) . . . 340

without otorrhcea trepanning; hearing recovered; absolute cure

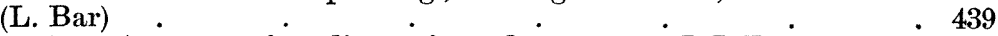
(azute) : prevention, diagnosis, and treatment (I. I. Thomson) . 584 (W. Stuart-Low) with acute suppurative inflammation of middle ear, blood: clot dressing in (F. L. Jack) .

(double), complicated by an intercommunicating sub-occipital abscess (H. B. Hitz).

Maxilla (superior) and ethmoid, osteomyelitis of, with suppuration in sinuses and in orbit (Dr. van der Wildenberg) . . . 394

-1 total resection of, for carcinoma (Dr. Goris) $\quad . \quad 1 \quad 396$ $\begin{array}{llll}\text { (left superior), swelling over (J. Dundas Grant) } & \cdot & \cdot & 396\end{array}$

Maxillary sinus, cyst of (Dr. van der Wildenberg) $. \quad . \quad . \quad 394$

(left) : suppuration of left frontal and left maxillary sinuses, closure of wound, and irrigation (C. J. Symonds) . 92 sinusitis (caseous) : symptoms and diagnosis (Dr. Texier) $\quad .432$

MAYer (Emil), scleroma of the larynx . . . . 381

Meat, piece of, impacted in gullet, skiagram showing (D. R. Paterson) . 229

Meatus (auditory), foreign body in, resembling fibrous polypus (Koenig) (external), aspergillus of, causing severe vertigo (A. Bronner) . . . . . . stenosis (W. H. Kelson) . chronic inflammation on both sides, with marked (inferior), nasal angeioma removed from (W. R. Kelson) $\quad \cdot \begin{aligned} & 344 \\ & \quad\end{aligned}$

Mechanico-therapeutics of ear (C. J. Blake). $\quad . \quad$. $\quad . \quad 402$

Ménière's disease : see Vertigo (aural). symptom-complex : see Vertigo (aural).

Meningitis following panotitis (G. S. Dixon)

\begin{tabular}{ccc}
- & removal of a polypus from middle turbinal (J. Merckx) & 433 \\
\hline (acute) ; operation ; recovery (E. A. Crockett) &. & 211
\end{tabular}

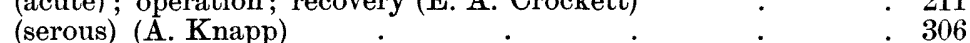

Menthol and eucalyptus pastilles (tabloid) $. \quad 1 \quad . \quad$. $\quad . \quad 440$

Mentholated throat tablets (modified) $\quad . \quad 168$

MENzEL (K. M.), the symptoms of empyema of the maxillary antrum (abstract)

a contribution to our knowledge of leukæmic changes in the mucous membrane of the upper air-passages and the digestive tract (abstract) .

Merckx (J.), meningitis following removal of a polypus from the middle turbinal

MraLl (L.), the organs of hearing in the lower animals $\quad . \quad$. $\quad 351$

Microbic and toxic invasion, tonsil as portal of (A. Jacobi) $\quad$. $\quad . \quad 399$

Micrococcus neoformans, bacterial vaccine of, in treatment of inoperable cancer of fauces (S. Spicer) . tion (R. H. Scanes Spicer and Sir A. E. Wright).

Mikulicz' disease simulated by pseudo-leukæmia (Dr. Broeckaert) $\quad$. 434

MILLER (Frank E.), the cause of vocal nodules $\quad$. $\quad$. $\quad$. 337

Milligan (William), retrospect of rhinology, 1905 $\quad \cdot \quad \cdot \quad \cdot 5$

a case of malignant growth originating in the skin over the mastoid process - the influence of pregnancy and parturition upon certain forms of progressive deafness 
Milligan (William), remarks (communicated for him in his absence) at discussion on fixation of the stapes auditory nerve, with the auditory sense epithelium and with the nuclei in the hind brain

Mitral affections, paralyses of vocal cords in (G. Gavello) . . 110

Mole (Harold), a case of acute otitis media suppurativa, with prolonged high temperature, but without other serious symptoms

Morbid Growths Committee, Laryngological Society of London, report of

Morcellement, severe hæmorrhage from tonsil during (Heckel) $\quad .287$

Morgagni, ventricle of, laryngocele of ventricle connected with $(\mathrm{Dr}$. Labarre)

Morton (William Cuthbert), some new instruments for removing foreign bodies from the bronchi by direct bronchoscopy . $\quad 12$

Mosher (H. P.), inflammation of the frontal sinus.

- a speculum for the examination of the pyriform sinuses and the upper end of the cesophagus (exhibited at Brit. Med. Assoc., Annual Meeting, 1906)

discussion on sinus suppuration . $\quad \cdot \quad 542$

discussion on sinus suppuration .

- discussion on treatment of deviations of nasal septum . $\quad .628$ UNIER (Dr.), nasal syphilis with a progressive destructive course; death of the patient .

Moure (E. J.), suppurative phlebitis of the sinuses

Mouth, obscure lesion of (de phlebitis of the sinuses .

. . . . . $\quad .163$ and nose, fistula between, closure of (Luc) $\quad . \quad 5 \quad .288$

Mouth-breathing (W. Lincoln) . . . . . 385

Mutism (hysterical) (G. H. Makuen) : $\quad$ : $\quad$. $\quad$. 332

Nævoid changes in anterior extremity of middle turbinal bone, causing persistent unilateral headache (V. W. Wingrave) . $\quad 378$

Nævus of cheek (Mayo Collier) . $\quad . \quad 5 \quad . \quad 300$

Nasal cavity, voluminous papilloma of (S. King) $\quad \cdot \quad: \quad: 164$ guards, exhibition of (A. Wylie) . $\quad . \quad$. $\quad .301$ No. 34 tablets. $\quad: \quad: \quad . \quad 168$

obstruction (H. J. Davis) . $\quad . \quad$. $\quad$. 172

- passages, malignant tumour of : new mode of access in operation

for (A. Denker) . . . . . . . 302

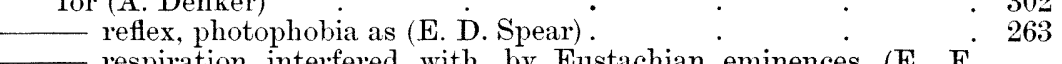

respiration interfered with by Eustachian eminences (E. F.

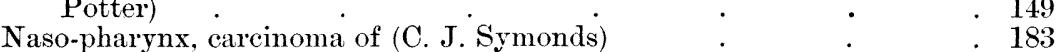

epithelioma of, microscopic section (W. Stuart-Low) $87,\left(\mathrm{~V} . \mathrm{W}^{\circ}\right.$. Wingrave) .

Wustachian eminences projecting into, interfering with free nasal

respiration (E. F. Potter) fibromata of (A. Capart) removal by enucleation (A. J. Brady) ${ }_{\text {. }}^{\text {. }}$ hæmorrhage (primary) from (Fiocre)

malignant growth in (P. R. W. de Santi)

sarcoma of, treatment by injections of adrenalin (J. E. Rhodes). polypus of, extirpation, death by collapse (Dr. Beco), (Lubet-Barbon).

Neck : deep penetration of dissecting abscess in neighbourhood of mas-

$$
\text { toid into neck (E. Urbantschitsch) . } \quad . \quad 290,291
$$
dermoid eyst of (V. W. Wingrave) . $\quad . \quad \cdot \quad \cdot 23$ 
Neck : radiograph of revolver bullet in left side of (Dr. Bôval) .

Nerve (abducens), paralysis of, complicating acute middle-ear suppuration

(H. Hastings)

- (auditory), fibres of, mode of continuity with auditory sense epithelium and with nuclei in hind brain (J. Cameron and $W$. Milligan) .

- - (laryngeal, recurrent), adhesions fixing and dragging on, most probable cause of case of fixation of left vocal cord in cadaveric position (W. Stuart-Low) question (A. Kuttner) critical observations on present position of " recurrent"; (sixth cranial) paralysis of, and double optic neuritis in case of otitic extra-dural abscess (J. T. Barr)

- (laryngeal, superior and inferior) peculiar condition of sensory irritability of ( $G$. Boenninghaus)

(laryngeal, recurrent) disturbances of, following thyroidectomy (Dr. Goris)

NeUMANN (Heinrich), a child, aged eleven months, who suffered from transitory facial paralysis after a radical operation

- a patient who was attacked by an acute otitis after a nasal operation .

- a patient, aged sixty, who for four months had suffered from great pain in the ear and loud subjective noises .

preparation of abscess of both the temporal lobes and cerebellum a preparation in which the dura of the posterior fossa was displaced inwards, and the sinus compressed by a neoplasm the size of

a small apple and 'radical operations under local anæsthesia (abstract)

NeuMAYER (H.), the use of the cesophagoscope in diagnosis and treatment of foreign bodies in the cesophagus

Neuritis (double optic), with paralysis of sixth nerve, in case of otitic extra-dural abscess (J. S. Barr)

— (experimental, degenerative) of auditory nerves (Wittmaack)

Neuroses (reflex) of nasal origin (G. King) .

Newcomb (James E.), diseases of the trachea

Nodules (vocal), cause of (F. E. Miller)

Noises (loud), prevention of ear affections due to (A. H. Cheatie)

Nose : accessory sinuses, anatomy of (Van den Wildenberg) 263, (H. W. Loeb) diseases, diagnosis and treatment : skiagraphy as an aid to (C. G. Coakley)

Nase" function of accessory cavities (J. M. Ingersoll) .

(H. Tilley) . . ultimate results of radical operations on (Delavan) injection of cold paraffin for (J.Dundas Grant) paraffin injection for (W. Downie) diseases of, acute), followed by acute affections of eyes (E. Baumgarten)

at Hospit statistical report of depar sment of oto-rhino-laryngology 
Nose : inflammatory obstruction of, as an etiologic factor in production of sputa (W. P. Porcher)

injection of solid paraffin into, without anæsthetic (A. Wylie) :

- (malfunction of), how far are abnormalities of nasal septum responsible for (H. L. Swain) .

(mucous membrane of), inflammation of (P. E. Goldsmith)
ocular symptoms of nasal origin (H. Hastings)
operation on, followed by acute otitis (H. Neumann)
(operations on), anæsthetic technique for (A. de Prenderville)
papillomata of (J. B. Ball)
pathological conditions of, specimens and drawings (L. Turner)
(polypus of), "Polypus of the Nose" (1906), by Eugene S.

reflex neuroses of nasal origin (G. King) $\dot{ }$ remal of adenoid vegetations through the nasal passages by $\dot{a}$

new method $(\mathrm{O}$. T. Freer)

- rodent ulcer (A. Wylie) 102 , (V. W Wingrave

(Roman), subcutaneous correction of (D. C. Green)

- sarcoma of (J. Price-Brown

$\begin{array}{cc}- & 555 \\ - \text { operation results, statistical report (J. Price-Brown) } & 593 \\ \text { treatment by electro-cautery (J. Price-Brown). } & .593\end{array}$

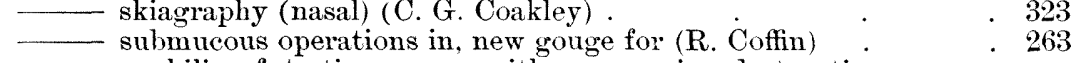

syphilis of, tertiary; case with progressive destructive course; death (Mounier)

$\longrightarrow$ treatment by iodides (Dr. Mahu) $\quad-\quad 68$

- tuberculous ulceration of (H. S. Barwell) . . . . $\quad 37$

- and mouth, fistula between, closure of (Luc). $\quad . \quad 5288$

Nostril, evacuation of ethmoid from (Dr. Collet) . . . . 395 (right posterior), bony occlusion of (H. S. Birkett) . $\quad . \quad \begin{array}{r}3 \\ \hline\end{array}$

Nourse (W. Chichele), a case of dysphagia $\quad \cdot \quad \cdot \quad 17$

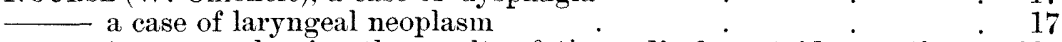

- two cases showing the results of the radical mastoid operation .189

Obituary : Stewart, William Robert Henry . _ . . . 213

Watson, William Spencer . $\quad . \quad 5.585$

Esophagoscope in diagnosis and treatment of foreign bodies in œsophagus

(H. Neumayer) . . . . . . . 210

Esophagotomy, removal of denture by (W. Downie) $\quad . \quad: \quad \cdot 129$

Esophagus, coin lodged in, at level of second dorsal vertebra (Dr.

Bôval)

distortion of, produced by vertebral ecchondrosis (Zahn) $\quad \cdot 394$

- diverticulum of entrance of ; operation (Capart) . $\quad .165$

—_ fish-hook removed from (D. R. Paterson) . $\quad . \quad 522$

- foreign body in (A. Coolidge, Jun.).

- impaction of piece of meat in, skiagram showing (D. R. Paterson)

obstruction of (J. Stewart).
cesophagoscope in diagnosis and treatment of foreign bodies in

(H. Neumayer) . . 210

- speculum for examination of upper end of (H. P. Mosher) $\quad .542$

\begin{tabular}{c}
- \\
\hline tooth-plate removed from (D. R. Paterson)
\end{tabular}$\quad . \quad 229$

Onodi (A.) "Die Nebenhöhlen der Nase" (review) . $\quad . \quad 404$

OPPENHEIMER (Seymour) report of a case of mastoiditis and temporo-

sphenoidal abscess ; operation; recovery
Oral infection, question of mutual communication of syphilis in three

cases by (H. J. Davis)
Orbit, suppuration in, in a case of osteomyelitis of superior maxilla and of ethmoid (Dr. van den Wildenberg) .
eitis of frontal bone (chronic). with chronic sinusitis (E. A. Peters) 
Osteomyelitis of cranium (diffused) following acute frontal sinusitis of staphylococcic origin, complicated with extra- and intra-dural abscess; cure (Luc) .

of jaw (Dr. Trétrôp)

of superior maxilla and ethmoid, with suppuration in sinuses and

in orbit (Dr. van den Wildenberg)

- (subacute) of frontal bone with empyema of right frontal sinus

(R. H. Scanes Spicer)

Othæmatoma, treatment of (Dr. Delstanche)

Otitis (acute) following nasal operation ( $H$. Neumann) media complicated by infective arthritis ( $P$. W. Eagleton) (purulent), abscess of brain following (Dr. Trétrôp) (chronic purulent) results of radical operation for

(S. MacCuen Smith) . (suppurative acute) : case with prolonged high temperature; no other serious symptoms (H. Mole) .

(Dr. Alexander) (chronic), four cases; recovery after operation

\section{(scarlatinal), operative treatment of (A. K. Gordon)} radical mastoid operation in (A. K. Gordon)

Otological Society of the United Kingdom: annual meeting and dinner

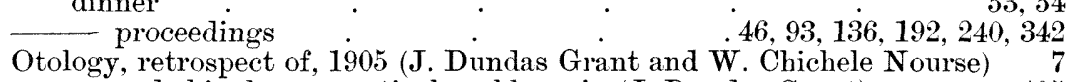
and rhinology, practical problems in (J. Dundas Grant) . 405

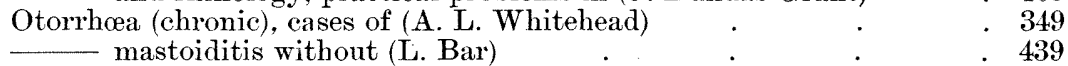

(old-standing), persisting after recovery from hip-joint disease

(Boulay)

Ozæna cured by submucous injections of paraffin (Dr. Broeckaert) $\quad \cdot \quad 396$

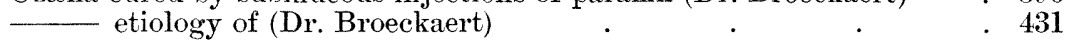

Palate, epithelioma of (J. Dundas Grant) . $\quad$. $\quad$. $\quad$. 238 lupus of larynx, palate, and pharynx (H. Barwell) $\quad . \quad 188$

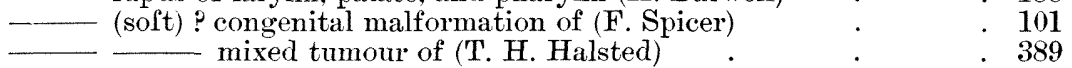

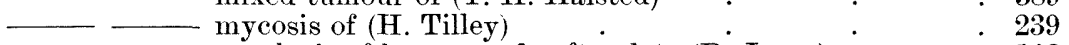

- - paralysis of larynx and soft palate (B. Jones) $\quad . \quad . \quad 103$

middle-ear with left recurrent paralysis associated with tuberculosis of soft palate, pharynx, and epiglottis

(Clayton Fox) . $\quad . \quad$. . . 234 tumour of ; twenty years' duration (J. W. Bond) $\quad . \quad 293$ ulceration of left posterior fold of (H. W. Carson) $\quad . \quad$. 184

Panotitis resulting in meningitis (G. S. Dixon) ․ . $\quad$. 166

Papilloma, fibroma of larynx recurring as, treated by laryngo-fissure

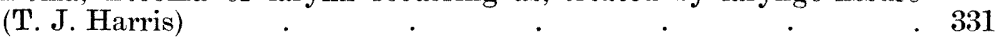

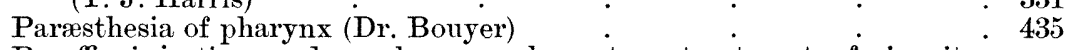

Paraffin injection, endonasal, as supplementary treatment of sinusites (Guisez)

$$
\text { for nasal deformity (W. Downie) }
$$
subcutaneous, for nasal and other deformities (A. B. Kirkpatrick) su)

Kirkpatrick) (cold) injection in case of nasal deformity (J Dundas Grant)
(soft and hard), normal and pathologic inclusion in tissues

(Dr. Broeckaert) (solid) injection into nose without anæsthetic (A. Wylie) 


\section{Index.}

Paralysis (abductor): paralysis of abducens nerve complicating acute

middle-ear suppuration (H. Hastings)
supplementary report of case of (G. L. Richards)
two cases (G. L. Richards)
months (H. Neumann) months (H. Neumann)

(left recurrent) and paralysis of soft palate, associated with middle-ear disease and facial palsy on same side (D. R. Paterson)

- of larynx and soft palate (B. Jones).

of posterior crico-arytenoid muscles, incomplete bilateral, tracheal

cannula worn on account of, nearly twenty-seven years (Sir F.

Semon) paralyses of vocal cords in mitral affections $(\dot{G}$. Gavello)

(pharyngo-laryngeal, unilateral) (Avellis' syndrome) (C. Poli)

(C. $\overline{\text { Poli })}$

Parisian Society of Laryngology, Otology, and Rhinology : proceedings

PARker (Charles A.), a case of swelling below the anterior commissure of the vocal cords, causing some dyspnoa, with deformity of the epiglottis and indurated swelling of both auricles, in a woman aged fifty-five

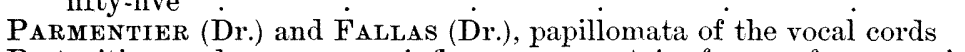

Parturition and pregnancy, influence on certain forms of progressive deafness (W. Milligan)

Paterson (D. R.), fish-hook removed from the cesophagus
skiagram of the neck in a case where a piece of meat was impacted in a structure in the nullet in a structure in the gullet

- tooth-plate removed from the oesophagus with middle-ear disease and facial palsy on the same side.

the operative treatment of laryngeal papillomata in children (abstract) .

Pathological conditions found in subject of deafness during life (A. A.

Gray) Pemington), case of secondary syphilitic lesions of the vocal the pathology, affinities, and treatment of so-called bleeding polypus (discrete angeioma) of the septum (abstract) . - bilateral ulceration of the posterior segments of the vocal cords in a man

Perichondritis of thyroid cartilage (Bosviel)

Peters (E. A.), case of chronic pharyngitis with polypi of uvula $\quad . \quad 42$

- a microscopic section of an angeio-fibroma.$\quad .78$

— a new nasal saw . $\quad . \quad . \quad . \quad . \quad . \quad .231$

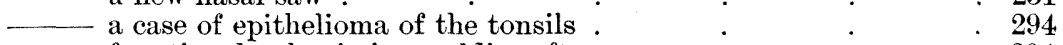

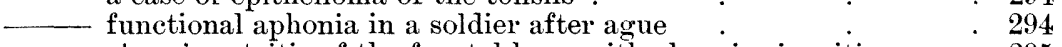

_. chronic osteitis of the frontal bone with chronic sinusitis $\quad .295$

Pharyngeal reflex (W. Baumann). $\quad . \quad 301$

Pharyngitis, chronic, with polypi of uvula (E. A. Peters) : 1092

Pharynx : abstracts of literature on $\quad$ 109, 202, 301

cancer (inoperable) of fauces, pharynx, tongue, and cervical

glands: amelioration after treatment with bacterial vaccine of

neoformans (R. H. Scanes Spicer and Sir A. E. Wright) . 265, 292

- endothelioma of (V. W. Wingrave) . $\quad . \quad$. $\quad .191$

- erysipelas of, primary (H. G. Langworthy) . . . $\quad 582$

- hyperæsthesia and paræsthesia of (Dr. Bouyer) $\quad \cdot \quad \cdot 435$

- lupus of larynx, palate, and pharynx (H. Barwell) 188

paralysis, pharyngo-laryngeal unilateral (Avellis' syndrome) (C.

Poli) . 
Pharynx : paralysis, association with paralysis of other muscles on same side (C. Poli)

(roof of), tumour of left half of face originating in (K. Jager) syphilitic ulceration in (extensive), rapid improvement under calomel injections (J. Dundas Grant) .

tuberculosis of soft palate, pharynx, and epiglottis (C. Fox)

- tumour of (J. B. Ball)

ulceration of pharynx and larynx (.J. B. Ball)

Grant) (probably specific), with unusual features (j. Dundas

Grant) and naso-pharynx, sclerotic hyperplasia of (A. Brown Kelly)

Philuips (Wendell C.), discussion on treatment of deviations of nasal septum

Phlebitis ( suppurative) of sinuses (Dr. Moure)

Photophobia as a nasal reflex (E. D. Spear)

Pinna, epithelioma of (M. Yearsley)

(H. S. Walker)

Pour (C.), A vellis' syndrome (abstract)

Politzer (A.), histological preparation from a case of suppuration of the labyrinth

Pollak (Professor), instrument for vibration massage of ear-drum - methods for carrying and keeping aseptic dressings and small instruments

Polypi (mucous) of choanæ, origin of (G. Killian)

$$
\text { of uvula, with chronic pharyngitis (E. A. Peters) }
$$

Polypus attached to diseased malleus, stereogram illustrating (J. K. Love) (bleeding): see Septum (nasal, angeioma, discrete.

(fibrous), foreign body in auditory meatus resembling (Koenig) .

(gigantic) removal (Dr. Lecocq) meningitis following removal of, from middle turbinal (J. Merckx)

(nasal) and sinusitis, recent, with long-standing atrophic rhinitis

(W. Hill)

(naso-pharyngeal) : extirpation; death by collapse (Dr. Beco) (Lubet-Barbon) (voluminous): operation by Lubet-Barbon's forceps

Ponthíkre (Dr.), psendo-membranous rhinitis $\cdot$.

Porcher (W. Peyre), discussion on congenital stridor, laryngeal and tracheal

discussion on conservative methods in treatment of aural diseases

discussion on laryngeal disturbances produced by voice use

inflammatory nasal obstruction as an etiologic factor in the production of sputa

Potrer (E. Furniss), case of fixation of right crico-arytenoid joint due to infiltration, probably malignant disease, in a woman aged fifty . case of swelling projecting from left tonsil (retention cyst) in a girl aged twenty-three

case of abnormally large Eustachian eminences projecting into the naso-pharynx to the extent of interfering with free nasal respiration

Pregnancy and parturition: influence on certain forms of progressive deafness (W. Milligan) . 280 ,

de Prenderville (A.), the anæsthetic technique for operations on the nose and throat (review)

Price-Brown (J.), a new operation for extreme cases of septal deflection, with presentation of a successful result in an adult case . 309 , 


\section{Index.}

Price-Brown (J.), discussion on treatment of deviations of nasal septum

Pritchard (Urban), introductory paper to discussion on fixation of the stapes

Pseudo-leukæmia simulating so-called Mikulicz's disease (Dr. Broeckaert) Pyæmia (otitic), ligation of internal jugular vein in (H. E. Jones)

(J. F. McKernon)

Pyriform fossa, piece of cartilage impacted in (R. Landesberg)

RAMON (de la Sota), obscure lesion of mouth (abstract) . . . 163

Rectum, ether narcosis by (J. A. Stucky) . $\quad . \quad 341$

"Recurrent" question, present position of (A. Kuttner) . 439

RENSHAw (Knowles), a case of fibro-sarcoma arising from the thyro-hyoid membrane .

Rhinitis, atrophic (H. J. Davis) : (W. Hill) long standing, with recent nasal polypus and sinusitis treatment by submucous injection of paraffin (A. B. Kirkpatrick)

(psendo-membranous) (Dr. de Ponthière)
$\begin{aligned} & \text { Rhinolith, specimen of (P. Watson Williams) } \\ & \text { Rhinology, retrospect of, } 1905 \text { (W. Milligan) }\end{aligned}$
$\begin{aligned} & \text { Rhino-phantom (Ky, practical problems in (J. Dundas Grant) } \\ & \text { RHoDEs (J. E.), sarcoma of the naso-pharynx; treatment by injections } \\ & \text { of adrenalin }\end{aligned}$ RICHARDS (George L.), discussion on conservative methods in treatment
of aural diseases

discussion on sinus suppuration two cases of abductor paralysis (Brit. Med. Assoc., Annual Meeting, Toronto, 1906) . . . . A supplementary report on case of abductor paralysis (Brit. Med.

Assoc., Annual Meeting, 1906)
what should be the attitude of public sanatoria towards cases of tubercular laryngitis, with suggestions as to the general plan of treatment of such cases in sanatoria

CHARDSON (Charles W.), some observations on non-traumatic per-

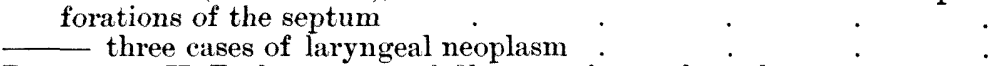

Robinson (H. Betham), case of fibro-angeioma of nasal septum $\quad .130$

Rodent ulcer on nose, excision of (A. Wylie) $. . \quad . \quad 102$

Roe (John O.), the ethmo-turbinal cells clinically considered . $\quad$. 326 discussion on the treatment of deviations of the nasal septum; introductory paper (Brit. Med. Assoc., Annual Meeting, 1906) ? 610

RUdoLF (R. D.), the medical treatment of exophthalmic goitre $\quad . \quad 55$

Saliva ejector (dental) as surgical instrument (R. H. Woods) . $\quad 61,162$

Sanatoria (public), treatment of cases of tubercular laryngitis in (G. L.

Richards)
DE SANTI (Philip R. W.), case of syphilitic granulomata and stenosis of the larynx; thyrotomy performed

a woman with immobile right vocal cord; previously shown May 5,1905 woman aged fifty with malignant growth in naso-pharynx; question of operation $\quad \cdot \quad 182$

Sarcoma, cases of (T. Hubbard)

SAUNDERS (E. W.), a plea for the more timely use of intubation in laryngeal stenosis, and for the use of tracheotomy in certain neglected cases 
Scarlatina: see Otitis (scarlatinal).

SCHEIBE : the therapeutical aspect of acute inflammations of the middle ear, with reference to their various etiology $\quad . \quad$. $\quad .307$

Schiffers (Dr.), epithelioma of larynx $\quad . \quad . \quad . \quad 396$

Semicircular canals, theory of function of (Dr. Barany) . . 361

SEMon (Sir Felix), a case of tumour in the interarytenoid fold, probably

tuberculous twenty-seven years on account of incomplete bilateral paralysis of the posterior crico-arytenoid muscles, which had remained unchanged all that time

Septum (nasal), abnormalities of, are they responsible for mal-function

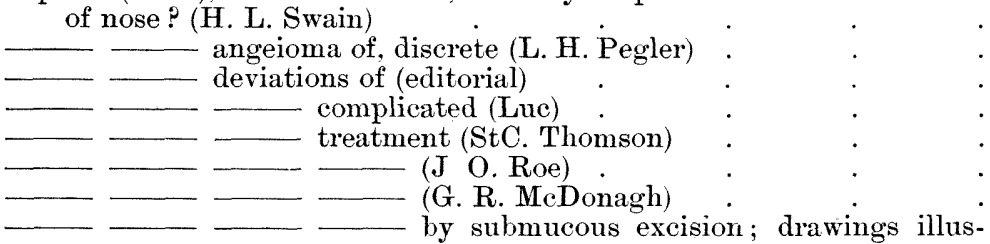

trating method of operation for (P. Watson Williams) . $\quad 582$

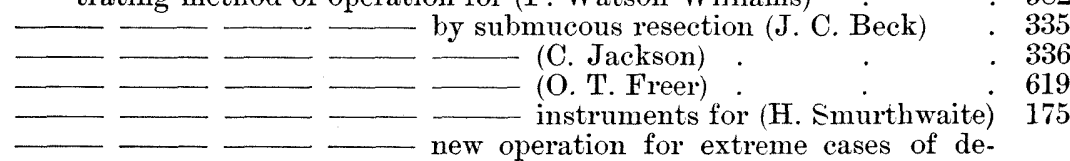

flection (J. Price-Brown) . . . $\quad 309,324$

- disease of ; case for diagnosis (F. Spicer) $\quad \cdot \quad \cdot 100$

\begin{tabular}{llll}
\hline fibro-angeioma of (H. B. Robinson) & $\cdot$ & $\cdot$ & 100 \\
\hline perforations of, treatment (M. A. Goldstein) & $\cdot$ & $\cdot$ & 337 \\
\hline non-traumatic (C. W. Swain) & $\cdot$ & $\cdot$ & 321
\end{tabular}

- results of operations on, by various incisions (J. F. Barn-

hill)

Shambaugh (G. E.), communications between the blood-vessels in the membranous labyrinth and the endosteum and those in the bony capsule of the labyrinth (abstract) - some relations of the blood-supply of the inner ear, which have a practical bearing on the clinical study of otology (abstract) circulation in the labyrinth of the ear (Brit. Med. Assoc., Annual Meeting, 1906)

- partial necrosis of cochlea and (H.S. Walker) . . 343

pathological preparations of (H. S. Walker) . . 351

Simpson (William K.), tracheal stenosis . • . . 329

Singer's nodes : cause of vocal nodules (F. E. Miller) $\quad: \quad: 337$

Sinus, closure with connective tissue (F. Alt) $\quad . \quad$. $\quad 289$ of chin (W. H. Kelson) . $\quad . \quad 69$ thrombosis, anatomical preparation showing cure of (F. Alt) 224 $\begin{array}{llll}\text { jugular vein in (W. P. Eagleton) } & \text { circulatory disturbances following ligation of internal } & \\ & . & . & \end{array}$ (J. Dundas Grant) treated by operation, without ligature of vein

Sinuses, suppuration in, in case of osteomyelitis of superior maxilla and of ethmoid (Dr. van den Wildenberg) . $\quad . \quad . \quad .394$ suppurative phlebitis of (Dr. Moure) $\quad: \quad \cdot{ }^{*} \quad .431$ 
Sinusitis (chronic), with chronic osteitis of frontal bone (E. A. Peters) (frontal) (H. P. Mosher) . . . 363 \begin{tabular}{ll}
$\cdot$ & \\
\hline & 363
\end{tabular} of staphylococcic origin complicated with extra-dural and intra-dural abscess, followed by diffuse osteomyelitis of cranium (Luc) (maxillary) (Dr. Trétrôp) . (caseous), symptoms and diagnosis (Dr. Texier) paraffin endonasally as supplementary treatment of (Guisez) rhinitis (W. Hill) (sphenoidal) with ocular complication (E. Delneuville).

treatment by operation, indications for (A. Capart, jun.)
Skiagraphy as aid in diagnosis and treatment of diseases of accessory
sinuses of nose (C. G. Coakley) sinuses of nose (C. G. Coakley)

- in diagnosis of frontal sinusitis (W. A. Chisholm)

- (nasal) (C. G. Coakley) . . . . . . . 323

Skulls showing different stages of operation for opening vestibule ( $R$. Lake)

Sмrтн (M. C.), discussion on treatment of deviation of nasal septum

Smith (S. MacCuen), the results obtained from the radical operation for chronic purulent otitis media

- the pathogenic influence of aural lesions in systemic disease (Brit. Med. Assoc., Annual Meeting, Toronto, 1906) . discussion on conservative methods in treatment of aural diseases

SMURTHWATE (H.), a patient shown in June, 1905, with thickening of right cord thought to be malignant; exhibited again for further diagnosis . _ instruments for submucous resection operation $\dot{ }$ discussion on conservative methods in treatment of aural diseases discussion on laryngeal disturbances produced by voice use - discussion on cold wire snare in removal of hypertrophied tonsils headache: pathological conditions of the middle turbinal a causal factor, 565. Discussion, Dundas Grant (President) (Brit. Med. Assoc., Annual Meeting, 1906) .

discussion on treatment of deviations of nasal septum .

Snare (cold wire) in removal of hypertrophied tonsils (A. S. Bryant)

"Sodium eitrate tabloid .

Sondermann's suction apparatus (j. Dundas Grant) .

Sound-waves, therapeutic effect of (C. J. Blake)
Spa : treatment of affections of throat, nose, ears, and eyes by carbonic acid gas at (E. Delneuville)

Spear (Edmund D.), photophobia : a nasal reflex (abstract)
Speculum for examination of pyriform sinuses and upper end of esophagus (H. P. Mosher)

SPICER (Frederick), case of disease of the septum, for diagnosis

SPICER (R. H. Scanes), multiple papillomata of the larynx in a man aged forty-one, which had recurred after three years' treatment ending fifteen years ago

a case of subacute osteomyelitis of frontal bone, with empyema of right frontal sinus, shown on May 5, 1905 . case of intrinsic laryngeal neoplasm in a man aged seventy-three, shown June, 1905

\section{8}

435

432

164 inoperable cancer of fauces treated with a bacterial vaccine of Micrococcus neoformans $\dot{0}$ inoperable cancer of the fauces, the pharynx, the tongue, and the cervical glands that has shown marked amelioration after treatment for ten weeks with a bacterial vaccine of neoformans 
SPILSBURY (B.), description of microscopical appearances in Dr. Scanes Spicer's case of inoperable cancer of fauces treated with bacterial vaccine of Micrococcus neoformans

Sputa, production of, inflammatory nasal obstruction as an etiologic factor in (W. P. Porcher)

Stammering, early treatment of, important (G. H. Makuen) . . 339

Stapes, fixation of (R. Lake) . . . . 357

- discussion on (Otological Society of United Kingdom) 240-262

STEWART (John), obstruction of the cesophagus (abstract) . 110

STEWART (William Robert Henry), obituary $\quad . \quad . \quad 213$

Stridor, laryngeal and tracheal, congenital : discussion (Annual Meeting, Brit. Med. Assoc., Toronto, 1906) . . 441

(laryngeal, congenital) (H. Koplik)
STUAR'-Low (W.), two cases illustrating the retention of the cholesteatomatous lining in the operation for acute mastoiditis, a sequel of chronic suppurative disease.

- case of epithelioma of the naso-pharynx, with microscopic section

\begin{tabular}{l}
\hline- \\
a case with greatly enlarged Eustachian cartilages \\
a case of ulceration of the auricular lobule of fifteen years' \\
standing \\
probably due to adhesions fixing and dragging on the recurrent \\
laryngeal nerve \\
case of cleft palate, showing that adenoids diminish the dyslalia \\
liquids of fixation of the right vocal cord with dysphagia for
\end{tabular}

STUCKY (J. A.), presentation of pathologic exhibit . $\quad . \quad$. $\quad .334$ ether narcosis by rectum . $\quad . \quad+. \quad 341$

discussion on conservative methods in treatment of aural diseases discussion on ligation of internal jugular vein in otitic pyæmia .

discussion on treatment of deviations of nasal septum.

larynx thyrotomy and laryngectomy for malignant disease of

Surgical instrument, dental saliva ejector as (R. H. Woods)

SUTHERLAND (G. A.), discussion on congenital stridor, laryngeal and tracheal

Swiss wrestlers, hæmatoma of right ear in (Valentin)

Suction apparatus (Sondermann's) (J. Dundas Grant)

Swarn (Henry L.), how far are abnormalities of the nasal septum responsible for malfunction of the nose?

Symonds (C. J.), suppuration of frontal sinuses treated by irrigation only

suppuration of the left frontal and the left maxillary sinuses closure of the wound and irrigation

Syphilis, congenital, case of (A. Wylie)

(hyperplastic, congenital), section of larynx and uvula from case of (A. Brown-Kelly) malignant disease of right side of larynx in syphilitic man

(StC. Thomson) of naso-pharynx (Furet) . three cases in one family (?) communicated mutually by oral infection (H. J. Davis)

- (tecondary), secondary lesions of vocal cord ( $\dot{\mathrm{L}} . \mathrm{H}$. Pegler) improvement under calomel injections (J. Dundas Grant) . $\quad$. 80 


\section{Index.}

Syphilis (tertiary) of nose: case with progressive destructive course; death (Mounier)

death (Mounier) . .0 .68

- ulceration of pharynx probably specific (J. Dundas Grant) 71

Syphilitic disease of larynx (M. Collier) . . . . 188

\begin{tabular}{cr} 
granulomata and stenosis of larynx; thyrotomy (H. S. Barwell) & 39 \\
\hline &
\end{tabular}

Syringe, aseptic (V. W. Wingrave) . 108

for intra-tracheal injections, made entirely of glass (Koenig) $\quad . \quad 285$

Syringomyelia, laryngeal disturbances in (G. Gavello) . . 110

Tabes, larynx in (D. C. Green) . . 209

Temporal bone, anatomy of (H. Frey) 291

disease, diagnosis of complications of (A. L. Whitehead) 351

Whitehead) based on study of 135 fatal cases (A. L.

prations of (H. S. Walker) • $\quad \cdot 269$

Temporo-sphenoidal abscess and mastoiditis (S. Oppenheimer) $\quad \cdot 350$

TEXIER (Dr.), the symptoms and diagnosis of caseous maxillary sinusitis 432

Therapeutics : abstracts of literature on . . . 112, 167

Therapeutic preparations $\quad . \quad 5 \quad .211,440,656$

Theisen (Clement F.), tracheal tumours . . . . 328

Thimbles for making aseptic wool mops (E. C. Baber) $\quad . \quad 572$

Thomson (J. J.), acute mastoiditis, its prevention, diagnosis, and treatment (abstract)

Thомson (StClair), a con glottic stenosis

$\cdot 176$

— discussion on sinus suppuration . . . . . . 494

_ discussion on laryngeal disturbances produced by voice use $\quad . \quad 535$

__ discussion on cold wire snare in removal of hypertrophied tonsils 563 - case of bilateral tuberculous laryngitis, completely healed for

three years, without local treatment, in a man aged fifty-five .573

- case of extensive tuberculous laryngitis, no local treatment, complete healing causing stenosis of glottis, and requiring tracheotomy,

healing maintained since one year, in a woman aged forty .573 - case of bilateral frontal sinus operation (Killian) . $\quad .576$

- malignant disease of the right side of the larynx in a syphilitic man aged sixty . . . . . . - discussion on the treatment of deviations of the nasal septum:

introductory paper (Brit. Med. Assoc., Annual Meeting, 1906) 604, 630 - discussion on thyrotomy and laryngectomy for malignant disease of larynx

Thrasher (A. B.), papilioma of larynx from inhaling flames $\cdot$\begin{tabular}{ll}
$0^{\circ}$ & 651 \\
\hline & 380
\end{tabular}

Throat, diseases of, treated by carbonic acid gas at Spa (E. Delneuville) 167

- effects of tobacco upon (S. W. Langmaid) . . . 109

- endothelioma of ; tonsillar disease (J. A. Logan) : : $\quad .333$

-_ examination of, in chronic systemic infections (J. L. Goodsale) . 386

- (operation on), anæsthetic technique for (A. de Prenderville) . 308

- pathological conditions, specimens and drawings of (L. Turner) . 177

tablets, mentholated (modified) . . . 168

Thrombo-phlebitis of jugular bulb with cerebellar abscess (J. Dundas Grant . . . 113

- of superior longitudinal sinus complicating subperiosteal abscess

of forehead (V. Delsaux)
Thrombosis (infective sigmoid sinus), resection of internal jugular (H. B.

Ellis) (latent) of la • 335 (latent) of lateral sinus (Dr. van den Wildenberg) • . 436

- lateral sinus treated by operation without ligature of jugular

\begin{tabular}{lrr} 
vein (J. Dundas Grant) & $\cdot$ & 148 \\
\hline of sigmoid sinus, cases of (A. L. Whitehead) $\cdot$ & $\cdot$ & 348,349 \\
\hline pathological preparations of (H.S. Walker) & $\cdot$ & $\cdot$ \\
\hline and partial necrosis of cochlea (H. S. Walker) &. & .343
\end{tabular} 
Thyro-hyoid membrane, fibro-sarcoma arising from (K. Renshaw) . 169 Thyroid cartilage, perichondritis of (Bosviel) . . . 284 cland, abstracts of literature on

Thyroidectomy, disturbances of recurrent nerves following (Dr. Goris) $\cdot 395$

Thyrotomy for syphilitic granulomata and stenosis of larynx (H. S. Barwell) in treatment of malignant disease of larynx (ं். Jackson)

TILLEY (Herbert), four cases of chronic frontal empyemata operated on by a simplified Killian operation case of mycosis of the soft palate

some considerations upon certain factors in the diagnosis and treatment of suppurative lesions in the nasal accessory sinuses (Brit. Med. Assoc., Annual Meeting, Toronto, 1906)

- discussion on cold wire snare in removal of hypertrophied tonsil discussion on conservative methods in treatment of aural diseases discussion on thyrotomy and laryngectomy for malignant

disease of larynx discussion on treatment of deviations of nasal septum .

Tobacco, effects upon throat (S. W. Langmaid)

Tongue: cancer (inoperable) of fauces, pharynx, tongue, and cervical

glands ; amelioration after treatment with bacterial vaccine of neo-

formans (R. H. Scanes Spicer and Sir A. E. Wright) . 265

- - carcinoma of (G. E. Armstrong) . . . $\quad . \quad 54$

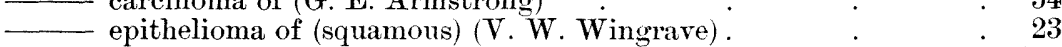

\begin{tabular}{lll}
- growth on left side of (P. R. W. de Santi) &. & \\
\hline
\end{tabular}

- malignant disease of (J. H. Bryan) . $\quad . \quad . \quad .386$

- ulceration (? malignant disease) of base of (W. H. Kelson) $\quad . \quad 581$

Tongue clip, exhibition of (P. Watson Williams) . . . . 582

Tonsil, hæmorrhage (severe) from, during morcellement (Heckel) $\quad . \quad 287$ (left), retention cyst of (E. F. Potter) . . . 134

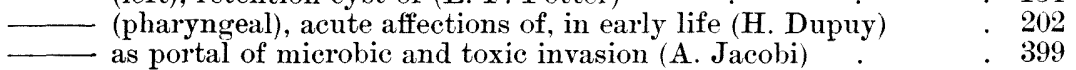

- (right) : new growth (? sarcoma) in region of right tonsil and

anterior faucial pillar (P. H. Abercrombie) . . . . 104

Tonsillar circle, lymphoid (G. Wishart) . $\quad . \quad$. $\quad . \quad 54$

Tonsils, epithelioma of (E. A. Peters) . . . . . . $\quad 294$

- endothelioma of throat; tonsillar disease (J. A. Logan) $\quad$. 333

hyperkeratosis of, etiology (G. B. Wood) . . $\quad 387$

- (hypertrophied), cold wire snare in removal of (A. G. Bryant) $\quad$. 556

Tooth-plate removed from the osophagus (D. R. Paterson) . . 229

Toxic and microlic invasion, tonsil at portal of (A. Jacobi) $\quad$. $\quad .399$

Trachea, diseases of (J. E. Newcombe) . . . 327

incrustations in, fatal termination of case (E. Law, G. C. Cath-

cart, and W. Jobson Horne) . . . . . 44,45

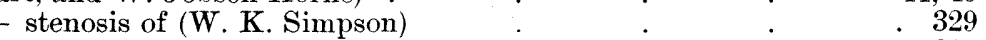

- tumours of (C. F. Theisen) . . . . $\quad 328$

Tracheotomy, " curative," in laryngeal tuberculosis (Henrici) . $\quad$. 653

foreign body extracted from bronchus by (Dr. van Swieten) . 398

\begin{tabular}{lll}
\hline- & \\
\hline
\end{tabular}

- required for stenosis of glottis following complete healing of

extensive tuberculous laryngitis (StC. Thomson)

- tube, radiograph of patient wearing, with revolver bullet lodged

in left side of neck (Dr. Bôval)

Tracheoscopy and foreign bodies (A. Coolidge, jun.) . $\quad . \quad . \quad . \quad 330$

Tragus (accessory), case of (A. Wylie) $\quad . \quad . \quad . \quad 301$

TRÉtrôp (Dr.), large abscess of the brain following purulent otitis media 391 presentation of instruments . . . . . $\quad 393$

sinusitis and osteomyelitis of the jaw $\quad . \quad+\quad . \quad .435$ 
Trow (C.), discussion on cold wire snare in removal of hypertrophied tonsils

Tuberculosis (laryngeal), galvano-cautery in (Dr. Escat)

of larynx (bilateral) healed without local treatment (StC. Thomson) of soft palate, pharynx, and epiglottis (C. Fox)

— tumour in interary tenoid fold, probably tuberculous (Sir F. Semon) $\quad \begin{array}{r}234 \\ \hline\end{array}$

Tuberculous ulceration of nose (H. S. Barwell) lesions absent in case of dysphonia (Koenig).

Turbinal (middle), meningitis following removal of polypus from ( $J$. Merekx)

pathological conditions of, a causal factor of headache

(H. Smurthwaite) bone (inferior), resection of (A. Forstelles)
(middle), nævoid changes in anterior extremity of, causing persistent unilateral headache ( $\mathrm{V}$. W. Wingrave)

PAGE

562

433

573

234

31

37

287

Turner (A. Logan), specimens and drawings illustrating various pathological conditions of the nose and throat

- a discussion on congenital stridor (laryngeal and tracheal); introductory paper (Annual Meeting, Brit. Med. Assoc., Toronto, 1906)

discussion on sinus suppuration

441,456

496
494

Tympanic membrane, abnormal colour of (M. Yearsley) $\quad \cdot \quad \cdot 138$

Tympanum, vibration-massage of, instrument for (Professor Pollak) : 226

Urbantschitsch (E.), a case in which Ménière's symptom complex was cured by a gynæcological operation abscessus dissecans profundus of an unusual type

URBantschitsch (Professor E.), a patient who had suffered from a discharge from the attic and headache for eighteen months

Uvula and larynx, lupus of (H. S. Barwell) . - pedunculated growth in (W. H. Kelson) polypi of, with chronic pharyngitis (E. A. Peters) section of, from case of hyperplastic congenital syphilis (A. Brown Kelly)

Vaccine (bacterial) of Micrococcus neoformans in treatment of inoperable cancer of fauces, pharynx, tongue, and cervical glands; amelioration (R. H. Scanes Spicer and Sir A. E. Wright) . inoperable cancer of fances treated by (S. Spicer)

VAIL (Derrick T.), herpes zoster auris

VALENTIN : on hamatoma of the right ear in Swiss wrestlers (abstract)

VAN DEN WILDENBERG: a contribution to the anatomy of the accessory sinuses of the nose (abstract). cyst of the maxillary sinus

401 osteomyelitis of superior maxilla and of the ethmoid, with suppuration in the sinuses and in the orbit a case of latent thrombosis of the lateral sinus

Ventricle, laryngocele of, air-containing cyst connected with left ventricle of Morgagni (Dr. Labarre)

Vertebra (second dorsal), coin in œesophagus at level of (Dr. Bôval) : 392

Vertebral ecchondrosis producing distortion of osophagus (Zahn) $: 304$

Vertigo (aural) : case of Ménière's symptom complex cured by gynæcological operation (E. Urbantschitsch) 
Vestibule (opening of), skulls showing different stages of an operation for (R. Lake)

Vibration massage of ear drum, instrument for (Prof. Pollak)

Vocal cord (left), fixation in cadaveric position, probably due to adhesions

fixing and dragging on recurrent laryngeal nerve (W. Stuart-Low) .

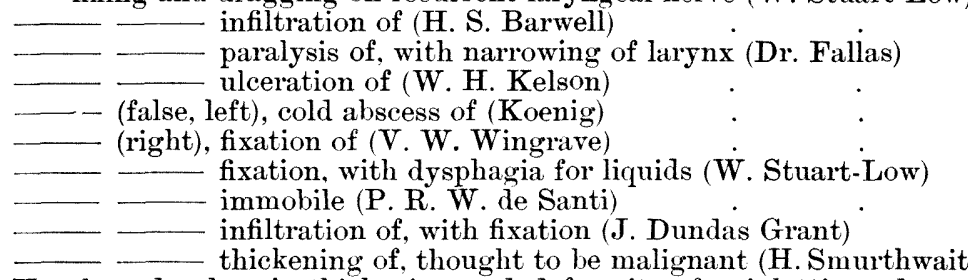

Vocal cords, chronic thickening and deformity of epiglottis and vocal cords (J. Donelan)

— papillomata of (Dr. Parmentier and Dr. Fallas)

paralyses in mityal affections (G. Gavello)

secondary syphilitic lesions of (L. H. Pegler).

swelling below anterior commissure of, causing dyspnoea, with

deformity of epiglottis, and indurated swelling of both auricles

(C. A. Parker)

(C. A. Parker) (bilateral) of posterior segments (L. H. Pegler)

Voice, sudden loss of (H. J. Davis)

use of, producing laryngeal disturbances (J. Middlemass Hunt) .

voN SwIETEN (Dr.), extraction of a foreign body from the bronchus by tracheotomy

WAGGETT (E. B.) a boy, aged seventeen, with absence of right choana . 133

WALKER (H. Secker), notes of an unusual and fatal case of cerebral

$\begin{array}{ccc}\text { abscess } & & 157 \\ \text { case of defective hearing from childhood; considerable recovery } & 342\end{array}$

partial necrosis of cochlea and sigmoid sinus thrombosis . 343

chronic mastoid disease; subdural abscess . . $\quad 347$

epithelioma of the extemal auditory meatus . $\quad . \quad 347$

epithelioma of the pinna; amputation $\quad . \quad 5 \quad .348$

_- pathological preparations of the temporal bone $\quad . \quad 5348$

- pathological preparations of sigmoid sinus thrombosis . $\quad 351$

Watson (W. Spencer) obituary .

WEST (C. E.) discussion on fixation of the stapes . . . . . 261

Wharton's duct, calculi of unusual size from (Koenig) $\quad$. $\quad$. 285

$\begin{array}{llr}\text { WHITEHEAD (A. L.) three cases of cerebellar abscess } & \cdot & 63 \\ \text { notes of three cases of cerebellar abscess } & \cdot & .\end{array}$

some points in the diagnosis of the complications of temporal

bone disease, based upon a study of 135 fatal cases . 269, 351

_ exhibition of cases of cerebral abscess, cerebellar abscess, sig-

moid sinus thrombosis, double mastoid disease, and chronic otor-

Whola

348,349

.$\quad .36$

discussion on sinus suppuration $\quad . \quad 5 \quad . \quad . \quad 494$

discussion on laryngeal disturbances produced by voice use $\quad 535$

- discussion on cold wire snare in removal of hypertrophied tonsils 562

a case of epithelioma of the larynx . $\quad .580$

drawings illustrating method adopted in operation for submucous

excision of septum.

exhibition of tongue clip $\quad \cdot \quad \cdot \quad \cdot 582$

discussion on treatment of deviations of nasal septum.$\quad .629$ 


\section{Index.}

WingRAVE (V. Wyatt), fixation of right vocal cord in a male aged fiftysix

ulceration of epiglottis in a female aged twenty-two. (congenital); (b) Squamous epithelioma of tongue from a woman aged forty-two; (c) Dermoid cyst of neck; $(d)$ Cyst of auricle

microscopical report on Mr. Stuart-Low's case of epithelioma of the naso-pharynx

- microscopic sections of Dr. D. Mackenzie's specimen of auricle removed for epithelioma of posterior surface

an aseptic syringe

"lichenoids"

microscopic specimens, with notes, of (1) angeio-myxoma of floor

of nose; (2) angeioma of larynx; (3) rodent ulcer of nose.

- microscopic specimens of endothelioma of pharynx, granuloma of auricle, epithelioma of larynx .

- notes on the pathology of fifty cases of innocent laryngeal growths preparations illustrating Dr. Dundas Grant's case of laryngeal growth shown by

persistent unilateral headache due to nævoid changes in the anterior extremity of the middle turbinal bone.

Wrshart (Gibb), the lymphoid tonsillar circle

discussion on congenital stridor, laryngeal and tracheal

WITTMAACK : on experimental degenerative neuritis of the auditory nerves (abstract)

- on the histo-pathological examination of the organ of hearing, with a special reference to the administration of fat and myelin substances (abstract)

Woon (George B.), etiology of hyperkeratosis of the tonsils .

Woops (Robert $H$.), on the dental saliva-ejector as a surgical instrument - the dental saliva-ejector as a surgical instrument exhibition of newly-designed forceps and elevators

Presidential Address at Annual General Meeting of British Laryngological, Rhinological, and Otological Association .

Wool mops (aseptic), thimbles for making (C. Baber)

Wright (Sir A. E.) and SpICER (R. H. Scanes), case of inoperable cancer of the fauces, the pharynx, the tongue, and the cervical glands that has shown marked amelioration after treatment for ten weeks with a bacterial vaccine of neoformans

Wrestlers (Swiss), hæmatoma of right ear in (Valentin)

WYuIE (Andrew), congenital specific disease injection of solid paraffin into the nose without an anæsthetic case of excision of rodent ulcer on the nose case of lymphangitis of the upper lip case of accessory tragu exhibition of nasal guards.

Xaxa tabloid

X-ray therapy in upper air-passages (L. Mader)

YEARsLeY (P. Macleod), sketch and specimen of a case of necrosis of the handle of the malleus patient, drawing, macroscopic and microscopic specimens of a case of epithelioma of the pinna case of abnormal colour of membrana tympani, shown for diagnosis

YoNGE (Eugene S.), polypus of the nose (review) 
688

\section{Index.}

$\mathrm{Z}_{\mathrm{AHN}}$ : a second case of distortion of the osophagus produced by

Zra (Noury), a rare case of foreign body in larynx (abstract) .

PAG E 
